IZA DP No. 10007

The Benefits of Alternatives to Conventional College:

Labor-Market Returns to Proprietary Schooling

Christopher Jepsen

Peter Mueser

Kyung-Seong Jeon

June 2016 


\title{
The Benefits of Alternatives to Conventional College: Labor-Market Returns to Proprietary Schooling
}

\author{
Christopher Jepsen \\ University College Dublin \\ and IZA \\ Peter Mueser \\ University of Missouri-Columbia \\ and IZA \\ Kyung-Seong Jeon \\ University of Missouri-Columbia
}

Discussion Paper No. 10007
June 2016

IZA

P.O. Box 7240

53072 Bonn

Germany

Phone: +49-228-3894-0

Fax: +49-228-3894-180

E-mail: iza@iza.org

Any opinions expressed here are those of the author(s) and not those of IZA. Research published in this series may include views on policy, but the institute itself takes no institutional policy positions. The IZA research network is committed to the IZA Guiding Principles of Research Integrity.

The Institute for the Study of Labor (IZA) in Bonn is a local and virtual international research center and a place of communication between science, politics and business. IZA is an independent nonprofit organization supported by Deutsche Post Foundation. The center is associated with the University of Bonn and offers a stimulating research environment through its international network, workshops and conferences, data service, project support, research visits and doctoral program. IZA engages in (i) original and internationally competitive research in all fields of labor economics, (ii) development of policy concepts, and (iii) dissemination of research results and concepts to the interested public.

IZA Discussion Papers often represent preliminary work and are circulated to encourage discussion. Citation of such a paper should account for its provisional character. A revised version may be available directly from the author. 


\section{ABSTRACT \\ The Benefits of Alternatives to Conventional College: Labor-Market Returns to Proprietary Schooling*}

This paper provides novel evidence on the labor-market returns to proprietary (also called for-profit) postsecondary school attendance. Specifically, we link administrative records on proprietary school attendance with quarterly earnings data for nearly 70,000 students. Because average age at school entry is 30 years of age, and because we have earnings data for five or more years prior to attendance, we estimate a person fixed-effects model to control for time-invariant differences across individuals. By five years after entry, quarterly earnings returns are around 32-35 percent for men and 25-26 percent for women. Average returns are slightly higher for associate's degree programs than certificate programs, but variation by field of study is much greater. Differences in return by gender are completely explained by differences in field of study.

JEL Classification: J24, I26

Keywords: postsecondary education, labor-market returns, proprietary schooling

Corresponding author:

Peter Mueser

Department of Economics

University of Missouri-Columbia

Columbia, Missouri 65211

USA

E-mail: MueserP@missouri.edu

\footnotetext{
* We thank seminar participants at IZA, the Stockholm School of Economics, the University of Jyväskylä, the London School of Economics, and the Society of Labor Economists / European Association of Labor Economists annual conference, Colorado State University, and Grinnell College for useful comments. We thank the European Commission (Marie Curie Career Integration Grants) for financial assistance. Several individuals in the state's Department of Higher Education provided invaluable assistance in procuring and interpreting the proprietary school data. All opinions and errors are the authors' sole responsibility.
} 


\section{Introduction}

The income distribution in the United States has widened over the last few decades. The relative earnings for high school graduates have declined substantially, and job opportunities for less-skilled workers are becoming more limited. States have drastically reduced funding for education, and public community colleges and universities are particularly hard hit (Phelan, 2014). Proprietary schools (also known as for-profit schools) have been growing dramatically over the last decade, filling a gap in demand for postsecondary education, particularly for lowincome and nonwhite individuals. Between 2000 and 2012, postsecondary enrollment increased by 302 percent in proprietary schools and 27 percent in public schools, so that nearly 9 percent of all postsecondary students were attending proprietary schools by 2012 (U.S. Department of Education, 2013). In response to concerns about false promises to students of future earnings and employment opportunities, state and the federal governments have increased oversight of the industry. However, lawmakers have little hard evidence on whether and to what extent these schools improve labor-market outcomes.

We provide novel evidence of the returns to proprietary school using administrative data. Specifically, we match enrollment data with quarterly earnings data for nearly 70,000 students who enrolled in the universe of proprietary schools in one state between 2005 and 2009. Our preferred model includes person fixed effects to control for time-invariant differences across individuals. This method is appropriate because the vast majority of students are over 20 years of age when they first attend, and we have earnings data for at least five years before enrollment.

We find sizable earnings returns to proprietary school attendance relative to the period 5 to 20 quarters before enrollment. By the fifth year after entry, quarterly returns are 32-35 percent for men and 25-26 percent for women. Average returns are slightly higher for associate's degree 
programs than certificate programs. For field of study, the highest returns are in computers, trades, and the "other” category, whereas returns for health, a field where women are much more likely than men to study, are considerably lower. Differences in overall training return by gender are completely explained by differences in field of study.

\section{Previous Literature}

Few studies have attempted to estimate the labor-market returns to proprietary schools due to limited data availability. Deming, Goldin, and Katz (2012) provide an overview of many aspects of the proprietary school market, including student outcomes such as employment and earnings six years after initial enrollment. Using the Beginning Postsecondary Survey (BPS), a national longitudinal survey of students, they find that individuals who had attended for-profit schools have lower annual earnings of approximately \$2,000 (contingent on being employed) and higher unemployment rates of 5 percent compared with students at not-for-profit institutions.

In contrast, other extant studies find little difference between proprietary schools and public postsecondary schools in labor-market returns. Lang and Weinstein (2013) also study BPS data, including transcript data. They find no difference in returns to associate's degrees between not-for-profit and for-profit colleges, and slightly smaller returns for certificates from for-profit colleges compared to not-for-profit colleges. They conclude that the variation in returns among fields of study is greater than the variation in returns between types of institutions, although their ability to disaggregate by field of study is limited by sample sizes of 400 and 700 in for-profit associate’s degree and certificate programs, respectively.

Cellini and Chaudhary (2014) use survey data from the National Longitudinal Survey of Youth 1979 (NLS79) to study the labor-market returns of for-profit colleges. They find that enrollment in an associate's degree program at a for-profit college corresponds with an earnings 
increase of roughly 10 percent conditional on employment, lower than the returns typically found for receipt of an associate's degree from community colleges such as in Jepsen, Troske, and Coomes (2014), Liu, Belfield, and Trimble (2014), and elsewhere.

Cellini and Turner (2016) use administrative data from the U.S. Department of Education to study labor-market returns to for-profit colleges among the subset of students who receive federal aid under Title IV of the Higher Education Act of 1965. They find that students in forprofit certificate programs have lower earnings returns than students attending certificate programs in public community colleges, and students exiting for-profit associate's degree programs experience declines in earnings after attendance.

Chung (2008) uses survey and transcript data from the National Education Longitudinal Study (NELS) to look at the returns to training programs provided by for-profit colleges. She finds little difference in employment between individuals attending for-profit colleges and individuals not attending colleges. She finds mixed evidence on the effects of for-profit college certificates and associate's degrees on earnings, but the inferences that can be drawn are limited by small sample sizes of students attending for-profit colleges.

Our work also complements recent audit studies. Darolia et al. (2015) and Deming et al. (2014) find that that CVs from for-profit colleges have substantially lower interview rates than otherwise identical CVs from traditional not-for-profit colleges. Thus, these studies suggest that employers do not view for-profit colleges as perfect substitutes for not-for-profit colleges and likely explain the lower returns to these schools in some of the previous work.

With the exception of Cellini and Turner (2016), ${ }^{1}$ all of these results are based on

\footnotetext{
${ }^{1}$ Liu and Belfield (2013) use administrative data to study the returns for students who transfer to a for-profit school after starting at a community college. They find that students have a significant wage penalty of transferring to a for-profit college.
} 
surveys, which rely on self-reported earnings. These survey datasets have relatively small numbers of respondents attending proprietary schools. Deming et al. (2012) focus on students attending Title IV-eligible institutions and Cellini and Turner (2016) focus on the subset of students who receive federal funding under Title IV. Both Deming et al. (2012) and Lang and Weinstein (2013) have data only for first-time students, and they acknowledge that many students in proprietary schools have previously attended college.

We contribute to this literature by using administrative data on the universe of proprietary schools and earnings. Our analysis of the entire set of schools and students in one state complement the previous work at the national level focusing on the subsample of students who attend Title IV-eligible institutions. Our final contribution is to explain why men and women have differences in returns to attendance; previous work has merely reported returns by gender rather than attempting to explain differences.

Because the state we study is representative of the nation in many respects, the results provide estimates that are plausible for many parts of the country. Such information is vital for lawmakers and policymakers as they aim to balance accountability of these schools with the need to allow flexibility in order to best meet the changing demands for postsecondary education.

\section{Data}

Our analysis focuses on students who entered proprietary schools in Missouri between January 2005 and December 2009. Our data are based on all schools certified by Missouri’s Proprietary School Certification Program. Nearly all the schools in the sample are for-profit schools. ${ }^{2}$ As in most states, the set of schools includes campuses of national institutions such as

\footnotetext{
${ }^{2}$ See http://dhe.mo.gov/psc/. Although the program formally requires certification of both nonprofit and for-profit post-secondary education programs, a variety of provisions exempt most non-profit post-secondary institutions. Almost all individuals in our analysis attended for-profit schools. We were able to identify the for-profit or not-forprofit status of all schools that accepted students in 2010. This set of schools accounted for 81 percent of individuals
} 
the University of Phoenix as well as local institutions focusing on one or two subjects such as truck driving academies. The data are not limited to schools that receive Title IV funding from the U.S. government. ${ }^{3}$ Although we know of no comprehensive listing that would allow us to identify whether all proprietary schools within the state are included, the analyses here are based on a more comprehensive listing of for-profit schools than that used in any previous analyses.

Our analysis focuses on entries of students who had not participated in a proprietary school program in the state in the 12 months prior to the observed program entry. ${ }^{4}$ In other words, we attempt to identify those attending proprietary school for the first time. ${ }^{5}$ The sample is limited to students who enroll in certificate or associate's degree programs because the vast majority of students in proprietary school enroll in these two program types. We exclude the small number of students who are coded as seeking a bachelor's or graduate degree, along with a very small set of students who declare some other degree or indicate that they are not seeking a certificate or degree. We also exclude students who indicate at the time of enrollment that they

\footnotetext{
analyzed in our sample. In this subgroup, 99 percent attended private for-profit institutions; private nonprofit institutions accounted for the remainder.

${ }^{3}$ The National Center for Education Statistics maintains a database that includes private for-profit schools, the Integrated Postsecondary Education Data System (IPEDS), but schools that are not eligible for federal student aid under Title IV are not required to be listed. Although almost all the for-profit schools listed in the IPEDS are included in Missouri's certification program, approximately 35 percent of the individuals in our analysis attended post-secondary schools that are not in the IPEDS database. Similarly, the U.S. Department of Education maintains a list of schools that are accredited by nationally recognized agencies (see http://ope.ed.gov/accreditation/), but only 40 percent of our sample attended schools with such accreditation.

${ }^{4}$ Our data include all those entering programs beginning in January 2004. For those entering in the early years of our analysis window (which begins in January 2005), entries will include some individuals who were attending proprietary schools in the year prior to entry but who entered before January 2004. We find that 4.5 percent of 2005 entries were omitted because of enrollment in the prior year, whereas the number was 11.3 percent for 2006 entries and about 14 percent for later entries. This suggests that up to 10 percent of those included as 2005 entries would have been omitted if we had full information on prior enrollment. The comparable figure would be under 3 percent for those entering in 2006. Note that if an individual enters a program within our window, then exits, and enters a program after a gap of more than 365 days, both entries are included in our analyses. Because of multiple entries by individuals, the number of entries exceeds the number of individuals by 2.4 percent.

${ }^{5}$ The results are nearly identical (available from authors upon request) if we include entries of students who had participated in a proprietary school program in the state in the 12 months prior to the observed program entry.
} 
are not permanent residents of the state or the neighboring state for which we have administrative earnings data.

For each student attending proprietary school during this time period, the data contain the specific school attended, the Classification of Instructional Programs (CIP) code with the field of study, the entry and exit date for each enrollment spell, and—-for award recipients—-the type of certificate or associate’s degree received.

These data are matched with administrative data on earnings from the state's and one neighboring state’s Unemployment Insurance (UI) program, providing quarterly earnings information from the first quarter of 1999 through the second quarter of 2015. Thus, we have data for at least five years prior to proprietary school attendance and a minimum of five-and-ahalf years (22 quarters) after initial enrollment in proprietary school. The resulting data set is a panel of student entries and time periods. We exclude observations where the individual is under the age of 18 or over the age of 60 at any time during the quarter, as well as any quarter of earnings more than 24 quarters prior to program entry or more than 30 quarters after program entry. We also exclude all observations for individuals where age, Social Security Number, or program exit date are missing. The number of individuals omitted for these latter reasons is very small.

\section{Methods}

To estimate labor-market returns, we compare the post-schooling earnings of an individual with the pre-schooling earnings of the same individual. In effect, the comparison group and the treatment group (to use experimental terminology) consist of the same individuals, so most of the measured and unmeasured factors that influence earnings are the same. 
This fixed effects model is a valid tool for estimating returns to schooling for individuals with pre-schooling earnings information. Economists regularly use fixed effects models to estimate labor-market returns for nontraditional students. Cellini and Turner (2016) and Cellini and Chaudhary (2014), cited above, use a student fixed effects model for measuring the labormarket returns to proprietary schools. Jacobson, LaLonde, and Sullivan (2005), Jepsen, Troske, and Coomes (2014), and others use student fixed effects models to estimate labor-market returns to community colleges. Such a model is appropriate for studying proprietary schools; over 80 percent of students in our data are age 20 or above when they initially enroll in proprietary school.

Following Cellini and Chaudhary, we focus on quarters with positive earnings. The fixed effects model fits the following multivariate regression:

$$
\begin{gathered}
\text { LNEARN }_{i t}=\alpha \cdot \text { ENROLL }_{i t}+\theta \cdot \text { ENROLL }_{i t} \cdot \text { ASSOCIATE }_{i}+\beta \cdot \text { PROPRIETARY }_{i t} \\
+\gamma \cdot \text { PROPRIETARY }_{i t} \cdot \text { ASSOCIATE }_{i}+\delta \cdot A G E_{i t}+\eta_{i}+\tau_{t}+\varepsilon_{i t} .
\end{gathered}
$$

In this equation, $i$ denotes a person and $t$ denotes a quarter. ENROLL is a categorical variable equal to one for quarters in which the individual is enrolled in school for the entire quarter and a value of one-half for the first quarter and last quarter of school enrollment. Because the school entry and exit dates are unlikely to coincide perfectly with the calendar quarter, we assume that individuals spend only a fraction of those quarters enrolled in school.

The input of interest is proprietary school attendance. The vector PROPRIETARY contains a set of dichotomous variables measuring time relative to enrollment at proprietary school. Specifically, we include variables for each quarter starting from the fourth quarter before enrollment. In other words, we include a variable for the fourth quarter before enrolling, a variable for the third quarter before enrolling, extending through the thirtieth quarter after 
enrolling. The variables for the four quarters before enrollment are included to capture the possibility of an "Ashenfelter dip" in earnings in the quarters immediately before enrollment, as Jepsen, Troske, and Coomes (2014) document large dips in earnings immediately prior to community college attendance. The reference period or omitted category is the set of quarters more than four quarters before enrollment. In other words, the coefficients report the difference in earnings for that quarter relative to quarters more than one year before entering proprietary school, taking account of age and calendar quarter effects.

We allow for different returns for certificate and associate’s degree programs by including a set of interaction terms between the dichotomous variables in PROPRIETARY and an individual-level dichotomous variable for associate's degree programs, ASSOCIATE, as well as an interaction term between the categorical enrollment variable ENROLL and ASSOCIATE.

$L N E A R N$ is the log of total reported UI earnings across all jobs for the quarter. Quarters with no reported UI earnings in a quarter are excluded. $A G E$ is the individual's age in years, represented by a cubic. $\eta$ is a set of person fixed effects, capturing all person-specific components that are constant over time, such as race/ethnicity or innate ability. The model also contains a set of dichotomous variables to control for each calendar quarter $(\tau)$. The last component $(\varepsilon)$ is the error term. As mentioned previously, we have earnings data from the first quarter of 1999 through the second quarter of 2015. Because we exclude observations more than 24 quarters before program entry and more than 30 quarters after program entry, we have up to 55 quarters of earnings observations per person. We estimate separate regressions by gender.

The quarterly variables for the quarters after initial enrollment provide a flexible way to capture the returns to attendance. We do not constrain the earnings to have any specific parametric relationship with the time since enrollment. Estimates of the impact of attendance are 
identified relative to the implicit counterfactual defined by the dummies for calendar quarter and age. ${ }^{6}$ Because the sample includes only individuals who attend proprietary schools, identification of the effects in post-participation quarters derives from comparing earnings for those quarters prior to participation and by the assumption that, given controls for age and calendar quarter, the patterns of schooling returns are similar for those beginning their attendance at different ages and in different periods.

We look at attendance rather than completion in order to avoid endogeneity concerns associated with non-random completion, as noted in Cellini and Chaudhary (2014) and Cellini and Turner (2016). Another, more practical, reason for the focus on attendance rather than completion is that, in those cases where the degree completed is not specified, this may indicate either that the individual left the program without a degree or that the information is missing.

The data also permit us to classify proprietary school enrollment spells by their area of study—for example computers or traditional trades such as construction—-to examine differences in impacts on labor-market outcomes. We estimate separate models of attendance by field of study. As men and women have very different distributions across fields, we examine the extent to which the differential overall returns by gender are due to differences in the distribution across fields and differences in the return within field by gender.

By design, our structure is only relevant for quarters in which individuals had observed earnings. As a complement to these analyses, we also fit a model that predicts expected employment:

$$
\begin{array}{r}
\text { EMP }_{i t}=\alpha \cdot \text { ENROLL }_{i t}+\theta \cdot \text { ENROLL }_{i t} \cdot \text { ASSOCIATE }_{i}+\beta \cdot \text { PROPRIETARY }_{i t} \\
+\gamma \cdot \text { PROPRIETARY }_{i t} \cdot \text { ASSOCIATE }_{i}+\delta \cdot A G E_{i t}+\eta_{i}+\tau_{t}+\varepsilon_{i t}
\end{array}
$$

\footnotetext{
${ }^{6}$ Although age is fit with a cubic, the results (available from authors upon request) were unchanged when we fitted age with a set of dummies for each age.
} 
Employment is a dichotomous variable equal to one for individuals with observed earnings. We estimate the model as a linear probability model.

There are several reasons that individuals may not be employed in a quarter. Given that our earnings measures capture employment only in the state where training occurred and one adjacent state, those who leave the state after completing schooling may have earnings elsewhere that we do not capture. Insofar as proprietary school attendance is associated with departure from the state, including quarters with no earnings will bias results. In contrast, individuals may have no observed earnings because they are unemployed or have left the labor market. Insofar as these latter employment differences reflect the impact of proprietary school attendance, we may wish to take them into account.

As a way to incorporate the possibility that individuals may have left the state, we have fitted the above model on a sample that omits quarters after enrollment ends if we observe no employment for an extended period through the end of our earnings data. In particular, if we observe no earnings in the last quarter for which earnings data are available, and the continuous string of quarters with no earnings subsequent to enrollment is at least 10 quarters in length, we omit this string of quarters from the analysis. This approach will fail to account for those who left the state after completing training and were employed elsewhere before resuming employment in the state, because the intervening years would be coded as including no employment. Conversely, this omits some individuals who are unemployed for more than 10 quarters or withdraw from the labor market because of poor opportunities. In each case, bias would result if these activities were associated with proprietary school attendance. 


\section{Results}

\section{Descriptive Statistics}

Table 1 contains the descriptive statistics for the analysis sample of nearly 70,000 entries for students into the state’s proprietary schools between January 2005 and December 2009. ${ }^{7}$ We provide statistics separately by gender and by degree program. The percentage white varies from 56.5 percent for women in certificate programs to 66.6 percent for men in certificate programs. The average age at entry is 27 years for associate's degree programs and 29 to 33 years for certificate programs. Approximately 75 percent have at least a high school degree; $15-20$ percent have a GED; around 2 percent in associate’s programs and 7 percent in certificate programs have less than a high school degree; and at most 2 percent have missing high school / GED status. Approximately 70 percent of students live in the state's major metropolitan areas, although only around 60 percent of the state's population as a whole lives in those areas (authors' calculations from 2010 Census). For men, over 76 percent pursue a certificate rather than an associate's degree, compared to only 69 percent for women. Completion rates are between 60 and 70 percent for certificates, compared to 50 percent or less for associate's degree programs. Over two-thirds of women pursue a degree in health as compared to less than 20 percent for men. For men, transport and trades are the most popular fields of study at roughly one-third each for certificates; the "other" category (including services and academic fields) is the most popular field for associate’s degree programs at 40 percent.

Figures $1 \mathrm{a}$ and $1 \mathrm{~b}$ (for men and women, respectively) present the trends in average earnings by quarter relative to quarter of entry, where 0 denotes the quarter of initial enrollment.

\footnotetext{
${ }^{7}$ Recall, the analysis sample is limited to entries into certificate or associate's degree programs, where the individual indicated permanent residency in the state or the neighboring state for which we have administrative earnings data, and where the individual had not been enrolled in a proprietary school in the state in the prior 12 months.
} 
Individuals with no reported earnings are coded as having zero earnings for the quarter, so the reported means are not conditional on employment. However, in order to exclude earnings for those who left the state, as noted above, we omit strings of quarters of length 10 or more where no earnings are observed after leaving school. As Figure 1a shows, men in certificate programs have noticeably higher earnings than men in associate's degree programs, although the gap narrows toward the end of the sample period. The difference can be traced to measured characteristics, most notably age. ${ }^{8}$ Both groups experience an “Ashenfelter dip” in earnings around the time of school entry, as well as reduced earnings following the entry quarter, often called a "lock-in" effect, reflecting participation in school. Because earnings growth is higher in the post-entry period than the pre-schooling period, average earnings exceed their pre-schooling levels a few quarters after school entry. The highest average earnings, observed 30 quarters after enrollment, are approximately $\$ 7,100$ per quarter for the certificate program and $\$ 6,300$ for the associate’s degree program.

For women, average earnings are much more similar for the two programs. Average earnings for the certificate program are higher in the pre-schooling period. After a substantial earnings reduction around entry, participants in both programs experience large increases in average earnings during the first few post-entry quarters, but then the rate of growth is more modest in later periods. From 9 quarters after entry until 30 quarters after entry, average earnings are slightly higher for associate's degree programs than for certificate programs. At the end of the sample period, average quarterly earnings are slightly under $\$ 5,000$ for both programs.

\footnotetext{
${ }^{8}$ Certificate degree seekers are nearly six years older, are more likely to enter the program in more recent years, and are more likely to be high school graduates than those seeking associate's degrees. Such differences are fully controlled in our regression estimates, which include individual fixed effects.
} 
For both men and women, these trends in average earnings strongly suggest positive impacts of participation. We now turn to regression results, which control for calendar quarter, age, and student fixed effects, for the estimates of the return to proprietary school attendance. Effects on Earnings

Figures $2 \mathrm{a}$ and $2 \mathrm{~b}$ contain the regression results for the model depicted in equation (1), again estimated separately for men (Figure 2a) and women (Figure 2b). The dependent variable is the logarithm of quarterly earnings. The figures show the returns to attendance for individuals pursuing certificates (dashed line) and associate’s degrees (solid line) for each quarter beginning four quarters before entry to 30 quarters after entry. The lines indicate the estimated increment in log earnings in that quarter relative to the period from 24 to five quarters before entry (the reference period), based on the combined effect of the coefficients for the dummy variables in PROPRIETARY and the coefficient for ENROLL. We use the average length of enrollment to determine the number of quarters of enrollment in each figure. For example, the average length of enrollment for men in certificate programs is about three quarters, so the dummy variable for enrollment is only included in the graph for quarters 0 to 2 in the graph, i.e., the first three quarters in which individuals are enrolled.

In equation (1), the coefficient for a given quarter of the PROPRIETARY variables is the return for attendance in certificate programs, whereas the return for attendance in associate's degree programs in a given quarter is the sum of that coefficient and the interaction term for the associate's degree program (the coefficient for one of the ASSOCIATE $\cdot$ PROPRIETARY variables in equation (1)). For example, in quarter 10, the return for certificate programs is 0.121 log points for men, and the interaction term between quarter 10 and associate's degree program is 0.014 . Thus, the return is $0.135(=0.121+0.014)$ for associate's degree programs, implying 
an increment of 14.5 percent. $^{9}$ Finally, note that the calendar quarter dummies included in equation (1) control for calendar quarter effects such as those due to statewide changes in wages due to inflation or variation in the health of the economy.

The figures show a broadly similar pattern for men and women: slightly lower earnings in the last four quarters before entry, a large decline around entry (somewhat less for men in associate's degree programs), followed by consistent gains in earnings for both program types. Earnings gains are higher and have a steeper earnings profile for men compared to women. By the fifth year after entry, ${ }^{10}$ the average earnings gain (relative to earnings more than one year prior to school entry) is 32 percent for those in certificate programs and 35 percent for those in degree programs.

For women, certificate programs are initially associated with higher earnings for most of the first eight quarters after entry, but in quarters 10 through 30, returns are essentially the same as those in associate's degree programs. In the fifth year after entry, average quarterly returns, relative to earnings more than one year before entry, are between 25 and 26 percent for both certificate and associate’s degree programs.

Because our preferred specification makes no distinction between individuals who complete an award and individuals who do not, we also estimate equation (1) where we limit the sample to individuals who have completed a certificate or an associate's degree. The decision to complete may be endogenous to labor-market outcomes, so we do not interpret the results as causal. For men, the results for completers in Appendix Figure A1 are very similar to the results in Figure 2a for the full sample, although returns in the last two years of our window are 2-4

\footnotetext{
${ }^{9}$ Because the average enrollment period is less than 10 quarters, the coefficients for the enrollment variables are not included in the estimated return in quarter 10.

${ }^{10}$ We choose five years or quarters 17-20 after entry because that time period corresponds roughly with the average post-schooling time period in Cellini and Chaudhary (2014), thus facilitating comparisons of our results with theirs.
} 
percentage points higher for completers. For women, completers (Appendix Figure A2) have higher returns after two years than the full sample (Figure $2 b$ ).

\section{Effects on Employment}

Figure 3a and 3b provide estimates of the effects of proprietary school enrollment on employment for males and females. Recall that this analysis omits quarters with zero earnings that are of length 10 or greater at the end of the earnings record following attendance, so individuals who permanently left the state do not contribute to this analysis after their departure. Employment during the period of enrollment for those seeking certificates declines by about 10 percentage points for both males and females during the second quarter of enrollment. Following enrollment, the estimate is positive, peaking around the fifth year after participants for both men and women in the range of 5-8 percentage points. By the end of our period, the increment is under 5 percentage points for women and close to zero for men.

For a woman seeking an associate's degree, the employment pattern is similar to that for those seeking certificates. For men seeking an associate's degree, effects on employment are somewhat anomalous during enrollment, indicating that enrollment is not associated with a substantial decline in employment. After exiting the program, effects on employment for men in associate’s programs are generally higher than for those seeking certificates, peaking at over 8 percentage points.

\section{Sensitivity Analysis}

In this section, we check the sensitivity of our preferred specification to alternative model and data specifications. The full set of results, which we summarize below, are available from the authors upon request. Both the earnings and employment results are quite similar if we estimate age as a series of dummy variables rather than as cubic. The results are also robust to 
excluding the relatively small share - under 20 percent - of students who attend part-time. Excluding the top one percent and the bottom one percent of earnings conditional on employment, a robustness test included in Cellini and Chaudhary (2014), does not affect the pattern of results. Because schools have substantial variation in how often they report exit dates, we estimate our models excluding participants attending schools with more than 20 percent missing exit dates during the year they entered, with no change in substantive results. When we include entries of students who had participated in a proprietary school program in the state in the 12 months prior to the observed program entry, we find little difference in returns, with the exception that the larger sample has smaller employment returns for men pursuing associate's degrees. Analyses of employment results are broadly similar when we change the length of the continuous string of quarters with no earnings subsequent to enrollment from 10 quarters to 15 quarters. $^{11}$

For earnings outcomes, the results are also robust to the following two changes: (1) restricting the sample to individuals who have positive earnings in at least one pre-enrollment quarter in our data set; and (2) excluding individuals who attended for less than one month. The results for employment vary slightly among these specifications compared with our preferred specification. Appendix Figure A3 shows the employment effects for men pursuing certificates, and Appendix Figure A4 shows employment effects for women pursuing certificates, both restricted to those who had positive earnings prior to enrollment. For both men and women, the estimated employment returns are lower if we limit the sample to individuals with some preschooling employment. This sample restriction excludes individuals with no labor-force

\footnotetext{
${ }^{11}$ Estimates of the effects of participation on employment up through three years following initial entry are not sensitive to this choice. Estimates for 4-7 years following initial entry are reduced by up to 3 percentage points when only strings of quarters of length 15 are omitted.
} 
experience prior to proprietary school entry, as well as individuals who have labor-force experience in states other than the two for which we have earnings data. Thus, it is not clear how to interpret this finding, other than to note the possibility that the employment effects for our preferred sample may be overstated if individuals with no pre-entry employment data in our two states are employed in other states prior to entry.

Figures A3 and A4 indicate that limiting the sample to students who attend for at least a month has different implications for men and women. When we exclude men who attend for less than a month (roughly a third of the sample), the employment returns are higher, suggesting that students with very short-term attendance derive fewer benefits than those who attend longer. For women, the results are very similar for the whole sample and for the subsample of people who attend for at least a month, in part because only 13 percent of the sample attend for less than a month.

Our final sensitivity test compares returns for individuals first enrolling in the first half of the sample period, January 2005 to June 2007 (earlier cohort), and returns for enrollees in the second half, July 2007 to December 2009 (later cohort). Here we use a single equation, but fit interaction terms that allow us to identify separate effects for each period. For earnings, although the returns are often slightly higher for individuals in the later cohort, generally differences are not statistically significant. For employment, the returns one to three years after enrollment are higher for the later cohort, but for subsequent returns, differences are not statistically significant.

In summary, the earnings returns are not sensitive to several different samples. Although the pattern of employment effects is consistent across the various sample definitions, the size of 
the return varies somewhat with the sample. However, the fluctuation in returns across samples is generally small, and often not statistically significant.

\section{Returns by Area of Study}

Because our data set provides information on area of study for nearly 70,000 students, we are able to obtain reasonably precise estimates of returns by estimating separate regressions for different fields of study. Figures $4 a$ (for men) and $4 b$ (for women) contain the earnings estimates based on the model presented in equation (1) for those pursuing certificates. The black line in each panel identifies the return to the specified area of study (e.g., under "business," the black line denotes the returns for business), whereas the grey lines show effects for each of the other subject areas, to allow comparison.

For men, if we look at the return for each area of study separately, we find that, with one exception, estimated effects on earnings for those in certificate programs are generally positive and statistically significant after two to three years following entry into the program. The exception is business, but this appears to reflect small sample size rather than lower estimated effects, as estimates are similar to those in transport and health, which are statistically significant.

Figure 4a makes clear that the six study areas can be divided neatly into two groups by average level of return. We see that men in business, transport, and health obtain earnings 15 to 20 percent above their predicted earnings in the absence of participation three years after entering the program, and are earning about 25 percent more at five years. Although these are good returns, those with areas of study in trades, computers, and the other category (which includes areas such as technology and services) have earnings increments that are several percentage points higher at three years (over 20 percent), with an increment that grows to over 
40 percent at five years. Although there are differences between the fields of study within these two groups, they are not statistically significant, and are small compared the differences between the two groups.

For women (Figure 4b), returns are similar to those of men within area of study, with the exception of trades and transport. Both of these are areas with very few women. In contrast to the case for men, where estimates for those in trades were above others, for women estimates for trades are somewhat lower than estimates for most other fields. But the statistical power for women studying trades is very limited, so that both zero and the highest estimates for any field are within two standard errors of effect estimates for women studying trades. We observe returns for transport that appear higher than the returns in most other fields, in contrast to the case for men, but because of the small sample, these returns are measured imprecisely. The difference between estimates for studying in transport for men and women are not statistically significant.

For the areas of study with substantial numbers of women, the relative returns are very similar to those for men, i.e., returns for business and health are below those in computers or the miscellaneous category. In fact, if we compare men and women within these categories, there are no statistically significant differences between men and women. This suggests that observed differences between men and women may be largely due to area of study. We now investigate this possibility in more detail.

Figure 5 provides returns for men and women in certificate programs averaged across all the fields of study. As expected, when returns for men are weighted by the distribution for men, the average is very similar to the effect estimate obtained in the basic model reported in Figure 2a. Similarly, women's weighted returns are similar to those in Figure 2b. The gap between the 
return for men and women grows after about quarter 10, and the difference is about 11 percentage points at 20 quarters and 20 percentage points at 30 quarters. However, when we weight the male returns by the female distribution, we see that returns correspond closely to that for the female distribution (dashed line). This indicates that observed differences between men and women in estimated returns are due to differences in the distributions of field of study. Almost all of the difference is due to the fact that 75 percent of women seeking certificates are in the health field, whereas the number is only 15 percent for men. Men are dramatically overrepresented in trades, a high return field, with 32 percent of certificate seekers in that area, compared to a mere 1.5 percent for women. ${ }^{12}$

We undertook comparable analyses by field for those in associate's degree programs. Because the sample size is appreciably smaller for both men and women, we do not present figures by field of study. Very few individuals in an associate's program list either trades or transport as a field, so our primary fields are business, computers, health and the other category. For both genders, computers and the other category have greater returns, corresponding with the results for certificates. For three of the four fields, business, computers, and the other category, the returns for men and women are very similar, and differences by gender are not statistically significant. The exception is health, where the return for women is appreciably higher than that for men. For women, the earnings increment for those in health approaches 35 percent by the end of our period, whereas for men, the increment is almost always less than 25 percent. In several quarters in the fifth and sixth years, the difference is over 15 percentage points.

\footnotetext{
${ }^{12}$ An alternative is to weight the estimated returns for women by the distribution for men, but we do not believe these results are meaningful, since they rely on the very imprecise estimates of returns for women in trades and transport.
} 
Figure 6 presents estimates of earnings effects for men and women in associate's degree programs based on weighting field of study returns by the number studying in each field, producing estimates that correspond closely to estimates reported in Figure 2. About 63 percent of women in associate's programs are in the health field, as compared with about 20 percent for men. When we estimate what returns for men would be if they had the same distribution across fields as women, this implies moving men into fields with lower returns than the fields in which they are observed. Average returns are also smaller than the returns for women in these fields due to the smaller returns from studying health for men than for women. Figure 6 shows that such weighting reduces the average returns for men to appreciably below those for women. Hence, our prior conclusion that the men's higher returns are entirely due to the distribution of their fields of study still holds. As in the case of those in certificate programs, higher returns for men can be traced to their lower representation in health. Men are overrepresented in the computer category and the other category, relatively high-paying fields for both men and women.

In conclusion, the difference in training returns between men and women can be traced to the difference in their fields of training. We have no evidence in any field-with one exception—-that returns for men and women differ. The one exception is that, among those in an associate's degree program, men studying in the health field have lower returns than women in the same field. The conclusion that there is no difference for other fields should be tempered by the recognition that, because women are very unlikely to pursue trades or transport, we have imprecise estimates of women's returns in those fields. Consistent with the stereotype, both for those seeking certificates and associate's degrees, women are much more likely to study in 
health fields than men, and our analysis shows that because returns are lower than in traditional male fields, this is the primary factor in explaining why returns for women are lower.

\section{Conclusion}

This paper investigates the relationship between proprietary school attendance and quarterly earnings. We use an individual fixed effects method to control for time-invariant differences between students. We find positive effects of attendance on earnings for students enrolled in certificate and associate's degree programs. Although men have higher returns than women, that difference can be entirely explained by field of study: the fields of study most men choose have higher returns than the fields most women choose.

How do our results compare to others in this literature ${ }^{13}$ Our results are in clear contrast to Cellini and Turner (2016), who find zero or negative earnings returns for proprietary school students who receive financial aid. Cellini and Chaudhary (2014) find a weekly earnings increment conditional on employment of around 10 percent in the four years after leaving school for young students in the NLSY attending associate's degree programs at for-profit institutions. If we look at a similar post-schooling time period, the average returns in quarters 5 to 20 - the first 4 years after an average attendance of 5 quarters in our data (i.e. quarters 0 to 4 ) - are approximately 18 percent for men and 16 percent for women. Thus, our estimates of the earnings increment resulting from attending an associate's degree program are larger than theirs when looking at the returns over the same time period. However, for longer post-schooling

\footnotetext{
${ }^{13}$ Because Deming et al. (2012) and Lang and Weinstein (2013) use data from the Beginning Postsecondary Survey, their preferred estimates compare proprietary schooling to public schooling rather than reporting overall returns as we do.
} 
periods, our analysis suggests that the returns to attendance grow, so that the effective benefits of attendance appear somewhat larger.

Jepsen, Troske, and Coomes (2014) find that students who complete associate’s degree programs in a Kentucky community colleges have higher quarterly earnings of 56 percent for women and 24 percent for men, compared to earnings increases of 7 percent for men and 5 percent for women for completing a certificate. Their time period of study is 4.5 to 6 years after entry, so we use our results for quarters 18-23 for comparison. We find smaller gains for women receiving associate’s degrees, 27 percent, but we find larger gains for men receiving associate’s degrees, 38 percent. Our estimates of the impact of a certificate are similar to our estimates for an associate's degree, so the impacts for certificates are appreciable larger than those of Jepsen, Troske, and Coomes (2014). ${ }^{14}$ However, it is difficult to compare results between our study and theirs because they focus on completion and estimate models that do not condition on employment.

For individuals pursuing certificates, we find that computers, the "other" category, and trades have higher returns than business, health, and transport. ${ }^{15}$ Although Lang and Weinstein (2013) find relatively smaller returns to certificates in vocational (i.e., trades and transport) and health areas, it is difficult to directly compare their results with ours because their returns by field of study include public as well as for-profit colleges. The pattern of results in Lang and Weinstein (2013) is similar to the pattern of results by field of study found in the Jepsen, Troske, and Coomes (2014) analysis of community colleges.

\footnotetext{
${ }^{14}$ If we compare employment outcomes, we find smaller effects for associate's degrees and larger effects for certificates.

${ }^{15}$ As noted above, we ignore estimates for women in trades and transport, given the imprecision of the estimates.
} 
With the exception of Cellini and Turner (2016), our results suggest that the benefits of proprietary school attendance are broadly similar to previous studies, at least for associate’s degree programs. We find larger returns to certificate programs than previous work on public community colleges. Although we find that earnings in the two years following program entry are appreciably below what they would have been, the earnings increment is positive and large in subsequent years, so that, at almost any reasonable discount rate, even allowing for substantial tuition expenses, the returns clearly justify the costs. However, in many time periods we cannot reject the hypothesis that the returns to an associate's degree program are equal to the returns to a certificate program despite the longer duration and, consequently, higher cost of the former. Finally, we find dramatic differences by field of study.

Overall, it would appear that the universe of students attending proprietary schools in this state are obtaining valuable labor market skills. But, perhaps not surprisingly, the benefits are not equally distributed. 


\section{References}

Cellini, Stephanie, and Nicholas Turner. 2016. Gainfully Employed? Assessing the Employment and Earnings Impacts of For-Profit Colleges Using Administrative Data. National Bureau of Economic Research Working Paper No. 22287.

Cellini, Stephanie, and Latika Chaudhary. 2014. The Labor-Market Returns to a For-Profit College Education. Economics of Education Review 43: 125-140.

Chung, Anna S. 2008. Effects of For-Profit Training on Earnings. Working paper.

Darolia, Rajeev, Cory Koedel, Paco Martorell, Katie Wilson, and Francisco Perez-Arce. 2015. Do Employers Prefer Workers Who Attend For-Profit Colleges? Evidence from a Field Experiment. Journal of Policy Analysis and Management 34(4): 881-903.

Deming, David J., Claudia Goldin, and Lawrence F. Katz. 2012. The For-Profit Postsecondary School Sector: Nimble Critters or Agile Predators? Journal of Economic Perspectives 26(1): 139-164.

Deming, David J., Noam Yuchtman, Amira Abulafi, Claudia Goldin, and Lawrence F. Katz. 2014, The Value of Postsecondary Credentials in the Labor Market: An Experimental Survey. National Bureau of Economic Research Working Paper No. 20528.

Jacobson, Louis S., Robert J. LaLonde, and Daniel G. Sullivan. 2005. Estimating the Returns to Community College Schooling for Displaced Workers. Journal of Econometrics 125(1-2): 271-304.

Jepsen, Christopher, Kenneth Troske, and Paul Coomes. 2014. The Labor-Market Returns to Community College Degrees, Diplomas, and Certificates. Journal of Labor Economics 125(1-2): 271-304.

Lang, Kevin, and Russell Weinstein. 2013. The Wage Effects of Not-for-profit and For-profit Certifications: Better Data, Somewhat Different Results. Labour Economics 24: 230-243.

Liu, Vivian Y. T., and Clive R. Belfield. 2013. The Labor Market Returns to For-Profit Higher Education: Evidence for Transfer Students. Paper presented at 2013 Education Finance and Policy Annual Conference.

Liu, Vivian Y. T., Clive R. Belfield, and Madeline J. Trimble. 2014. The Medium-term Labor Market Returns to Community College Awards: Evidence from North Carolina. Economics of Education Review 44: 42-55.

Phelan, Daniel J. 2014. The Clear and Present Funding Crisis in Community Colleges, New Directions for Community Colleges, 2014(168): 5-16.

U.S. Department of Education, National Center for Education Statistics. 2013. 2013 Digest of Education Statistics, Table 303.10, Washington, D.C.: U.S. Department of Education. 
Figure 1a - Quarterly Earnings by Program Type and Quarters since School Entry, Men

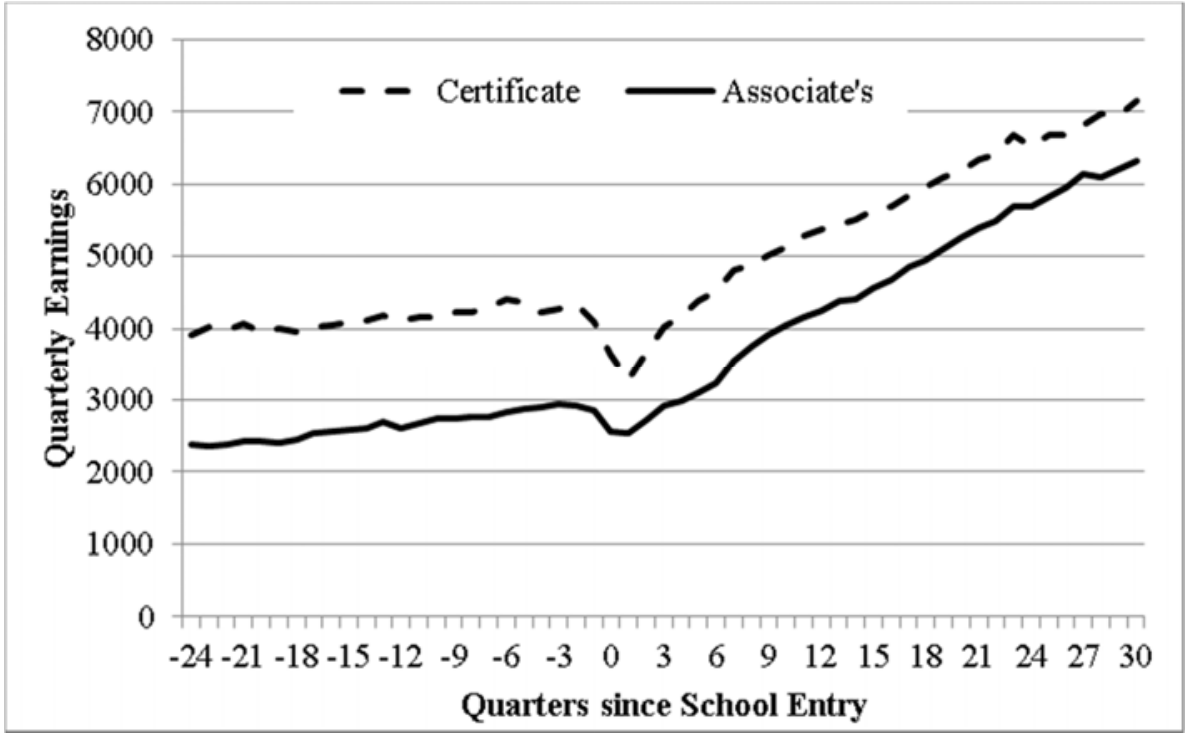

Figure 1b - Quarterly Earnings by Program Type and Quarters since School Entry, Women

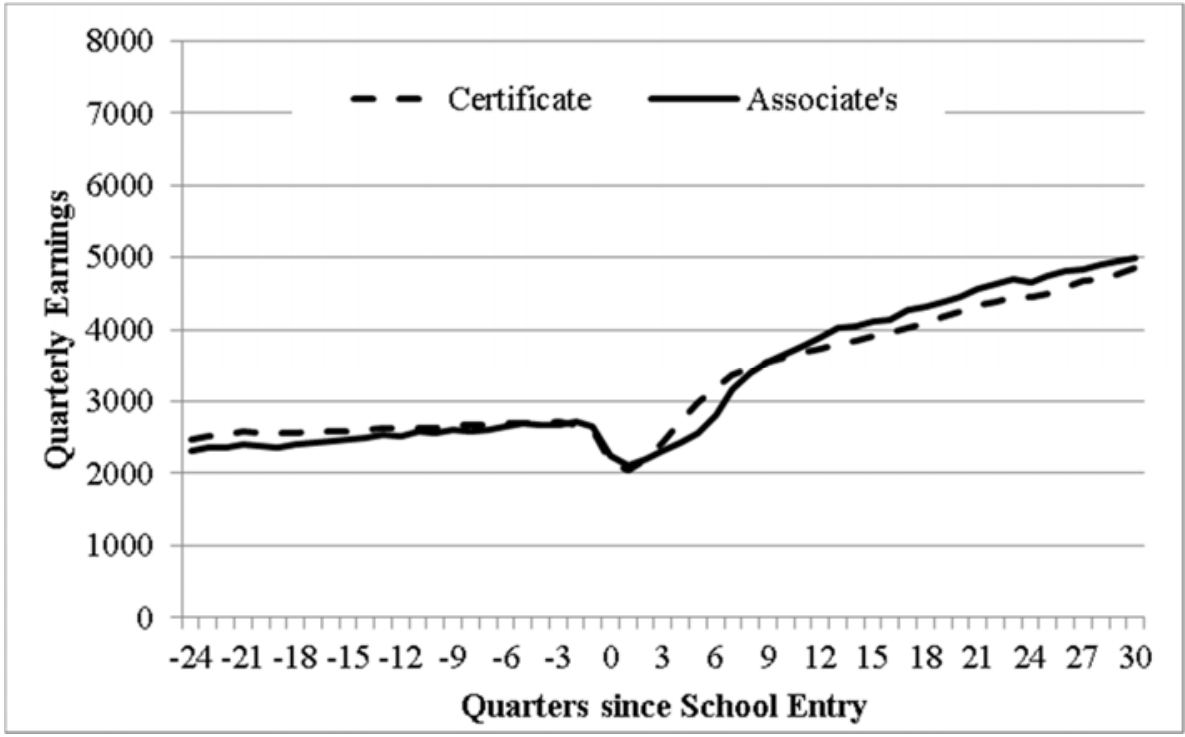


Figure 2a - Effect of Attendance on Earnings by Quarter and Program Type, Men

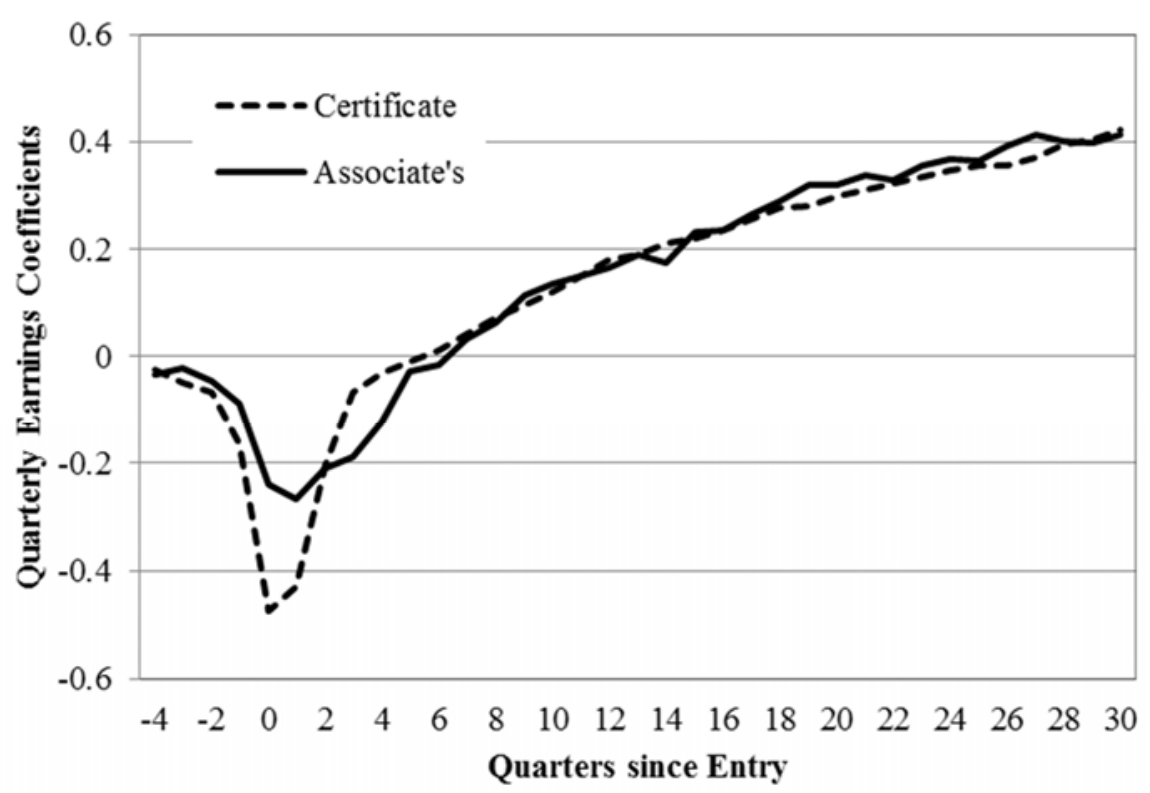

Figure 2b - Effect of Attendance on Earnings by Quarter and Program Type, Women

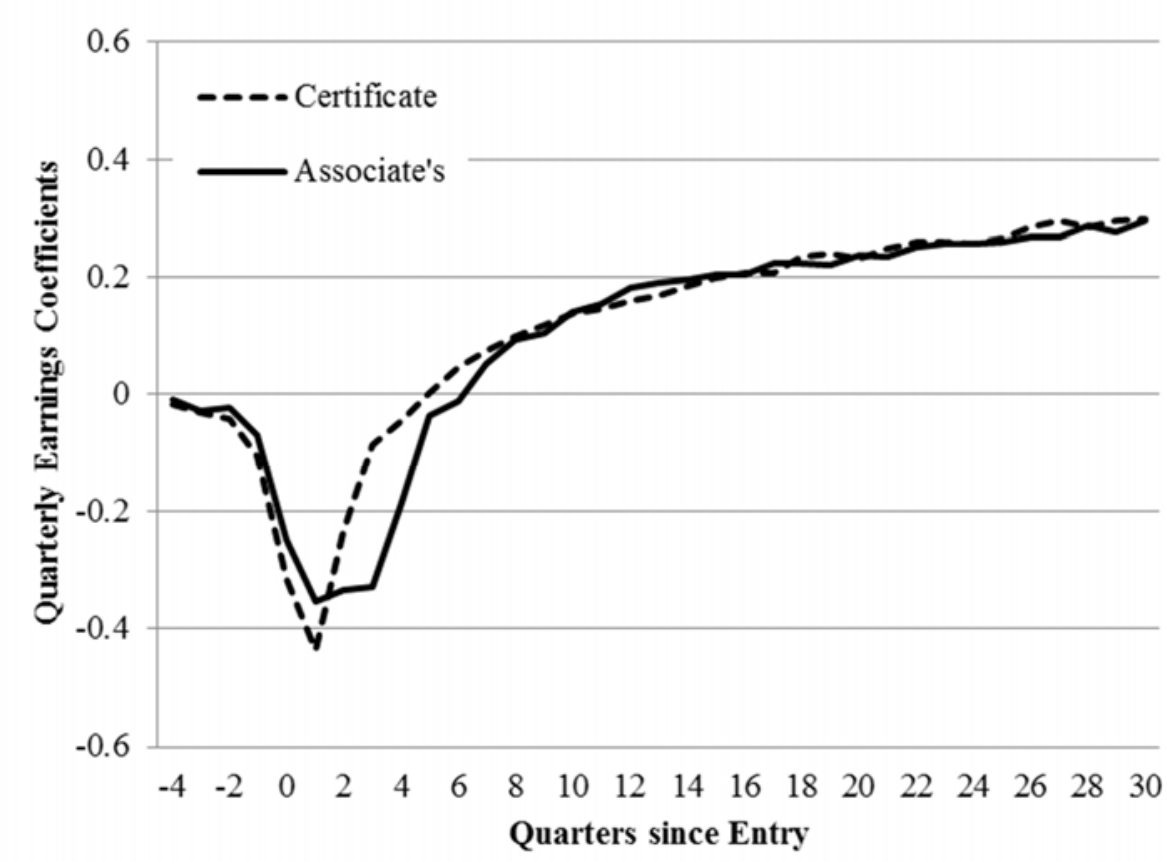


Figure 3a - Effect of Attendance on Employment by Quarter and Program Type, Men

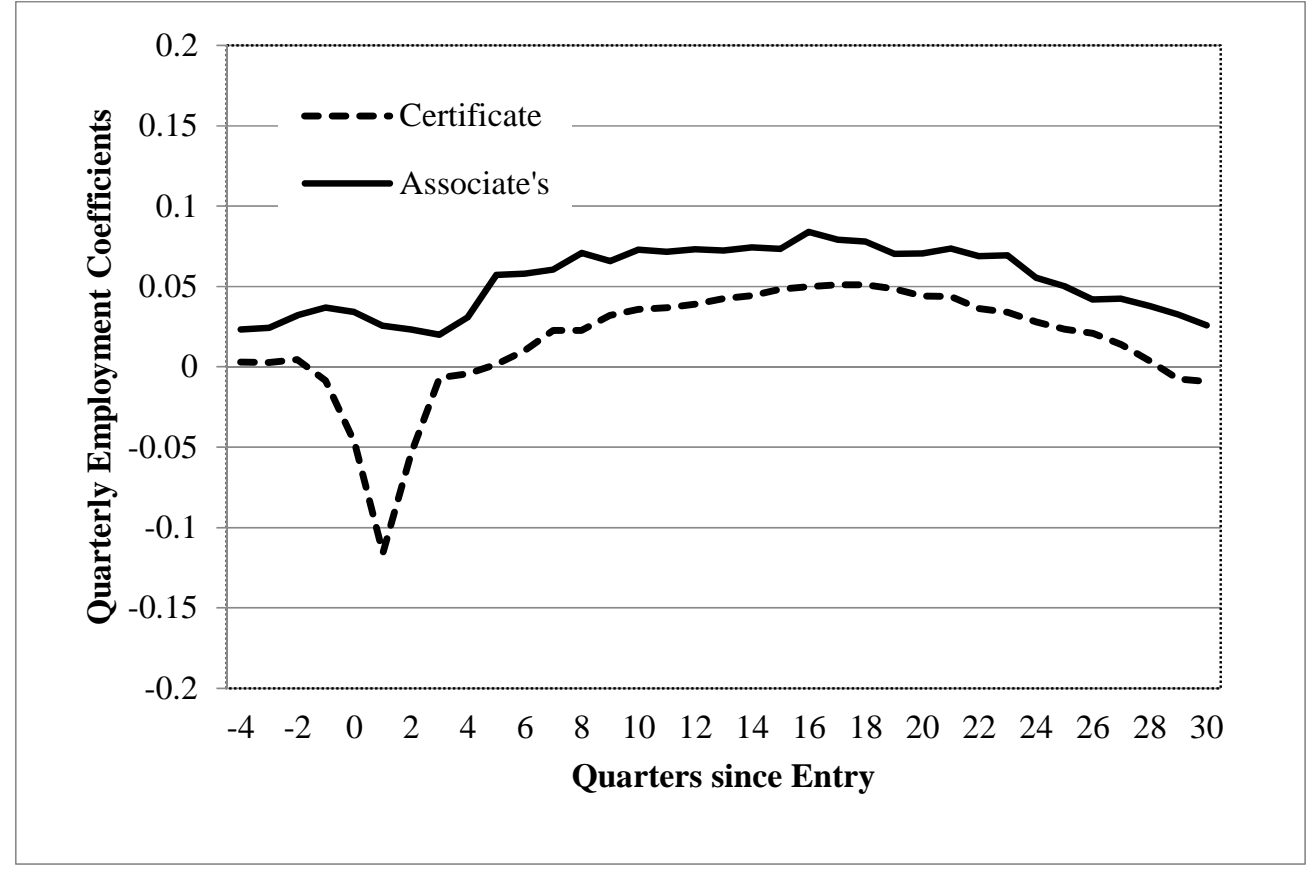

Figure 3b - Effect of Attendance on Employment by Quarter and Program Type, Women

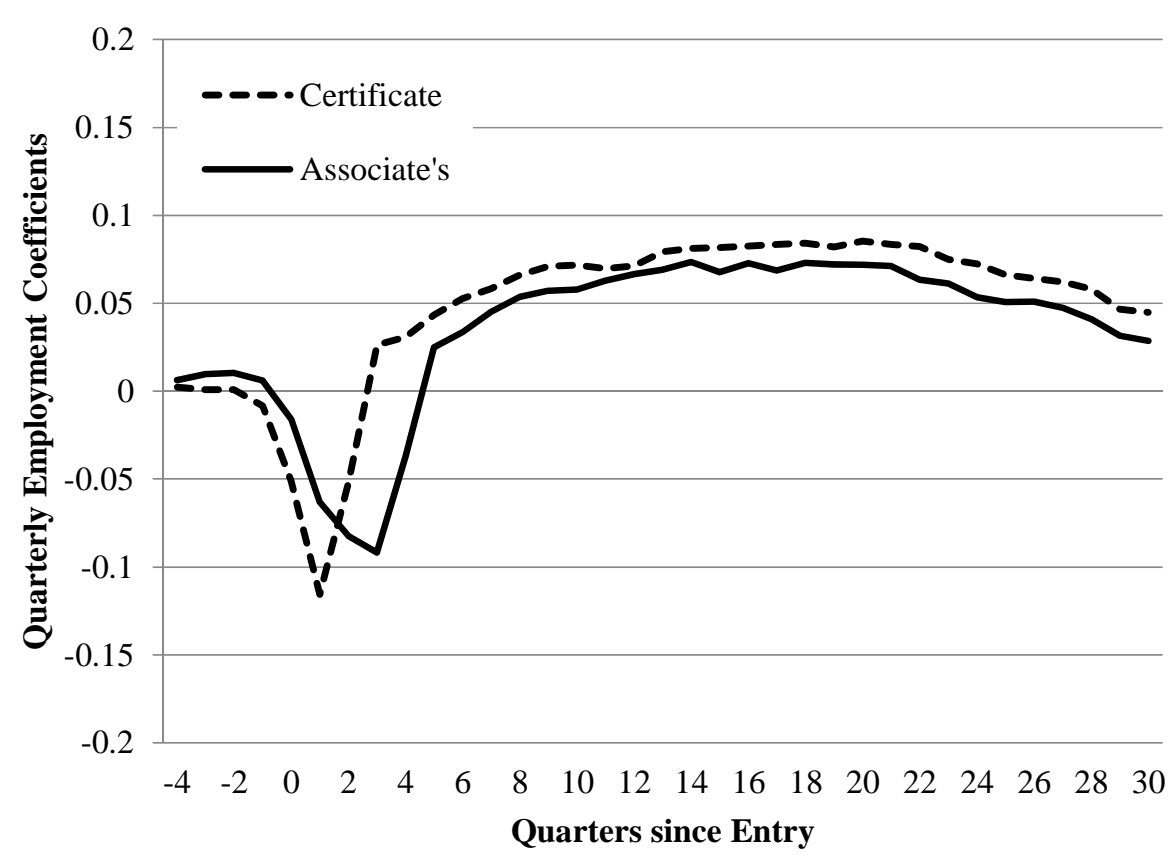


Figure 4a - Effect of Attendance on Earnings by Quarter and Field of Study, Men Certificate Programs Only

\section{Business}

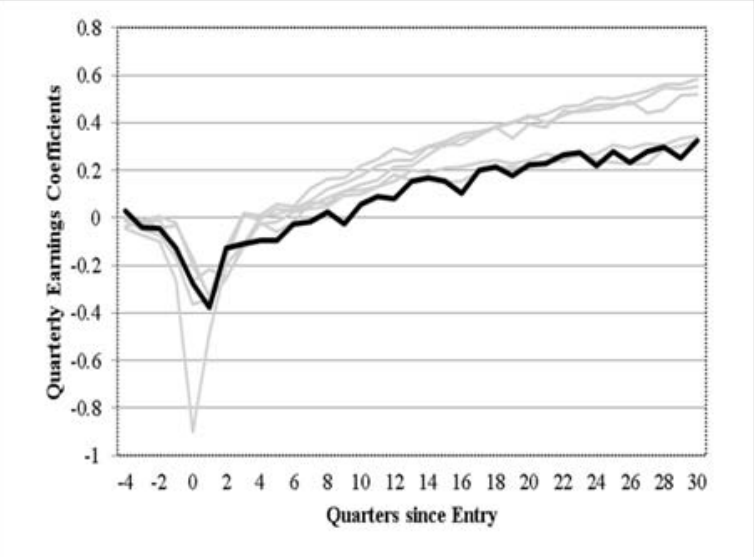

\section{Computers}

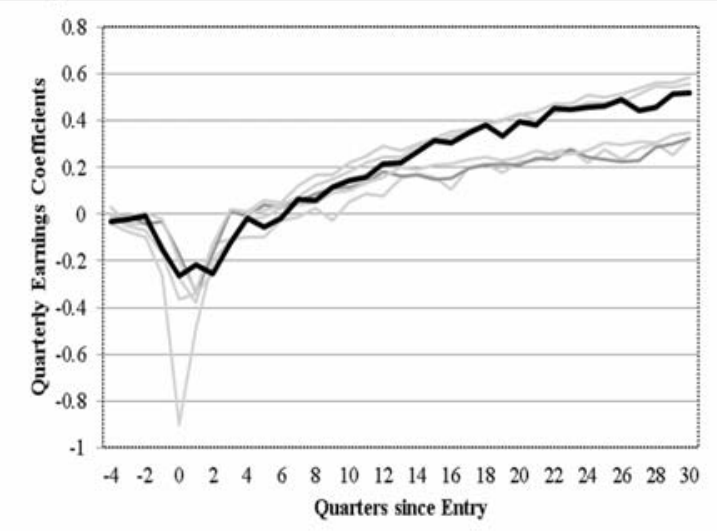

Health

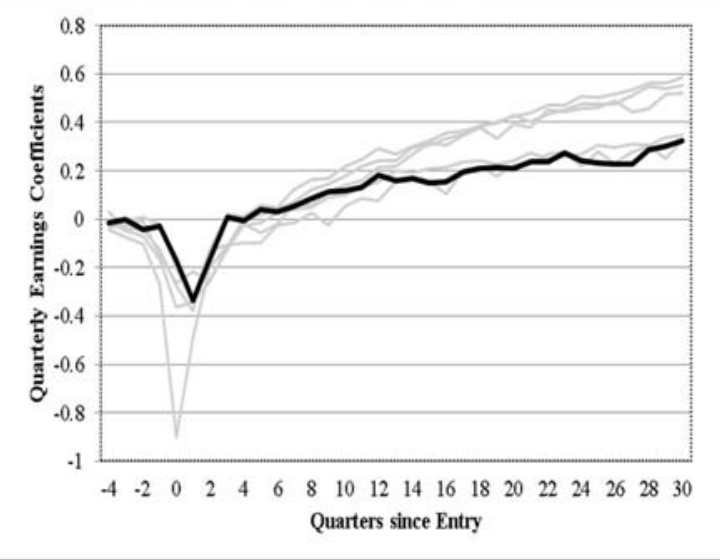

Trades

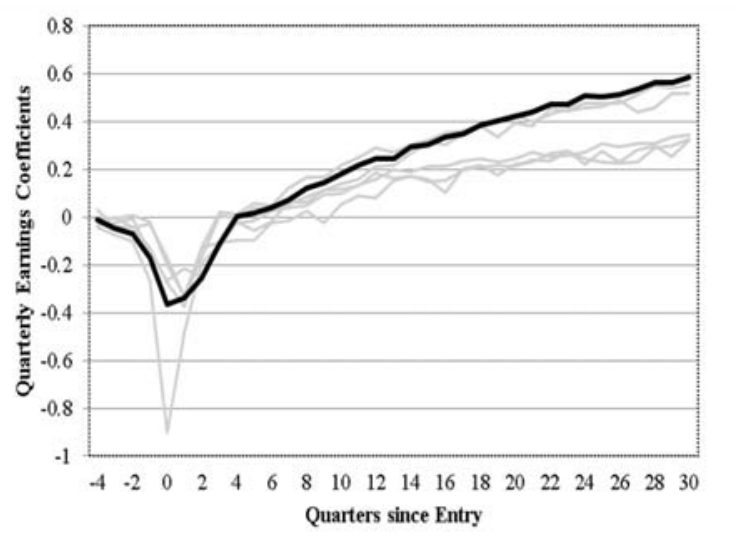

Transport

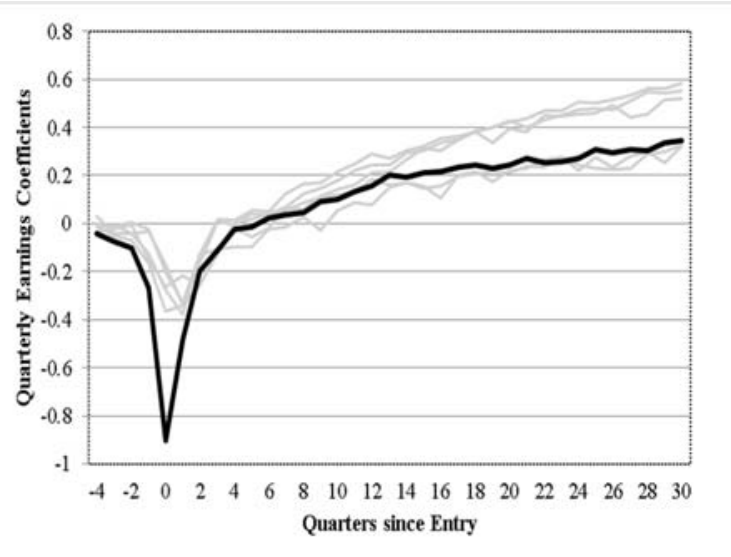

Other

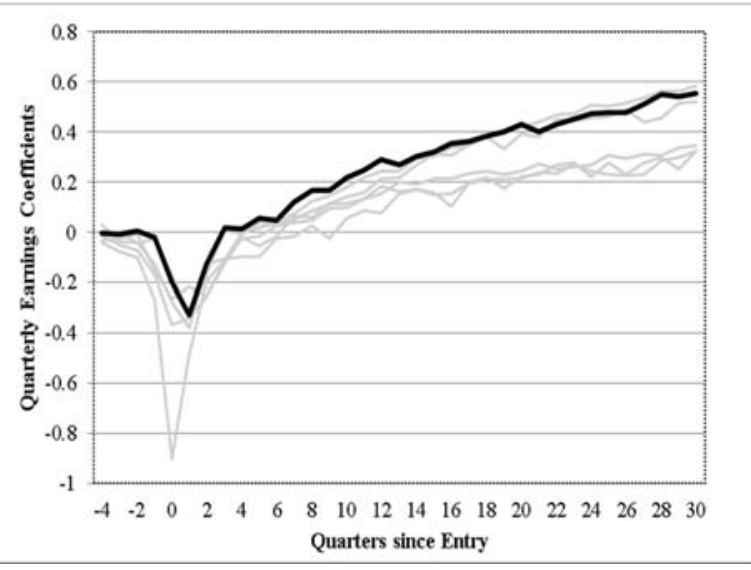


Figure 4b - Effect of Attendance on Earnings by Quarter and Field of Study, Women Certificate Programs Only

\section{Business}

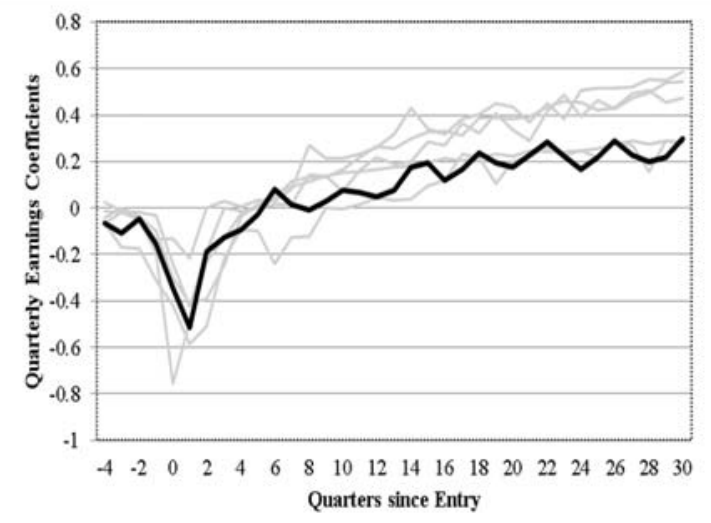

\section{Computers}

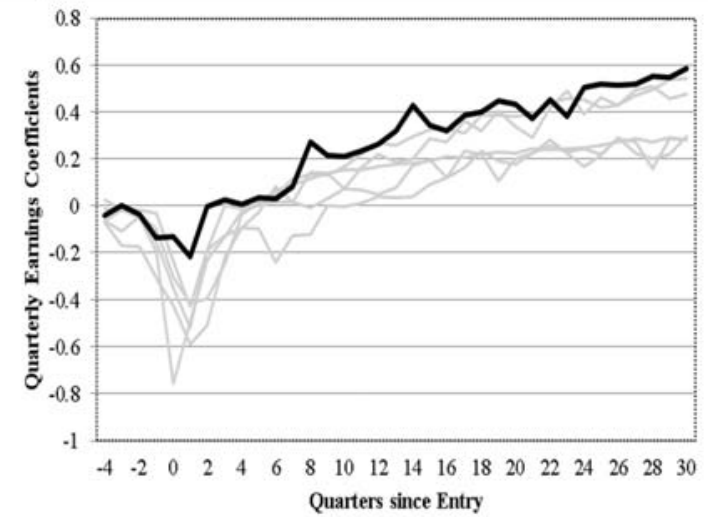

Health

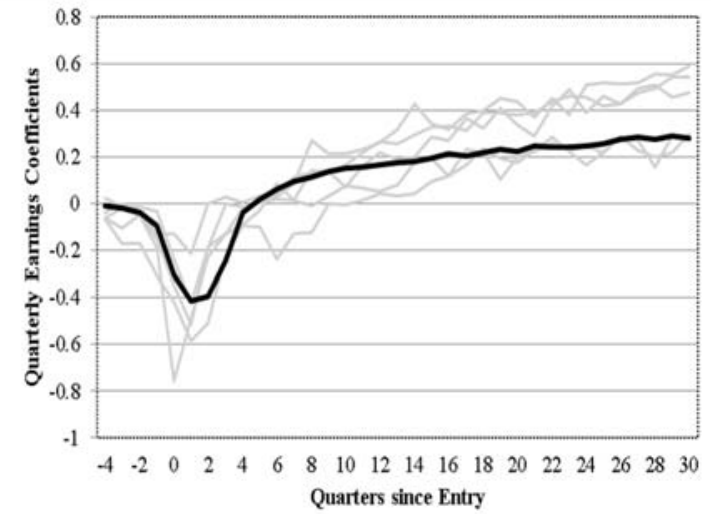

Trades

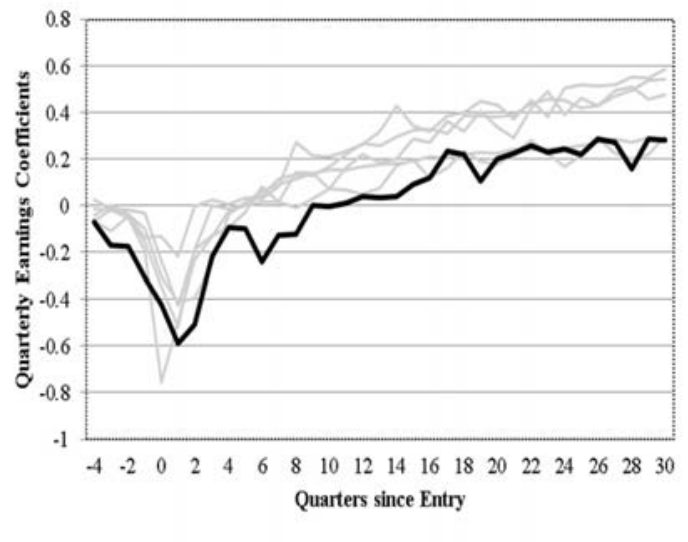

Transport

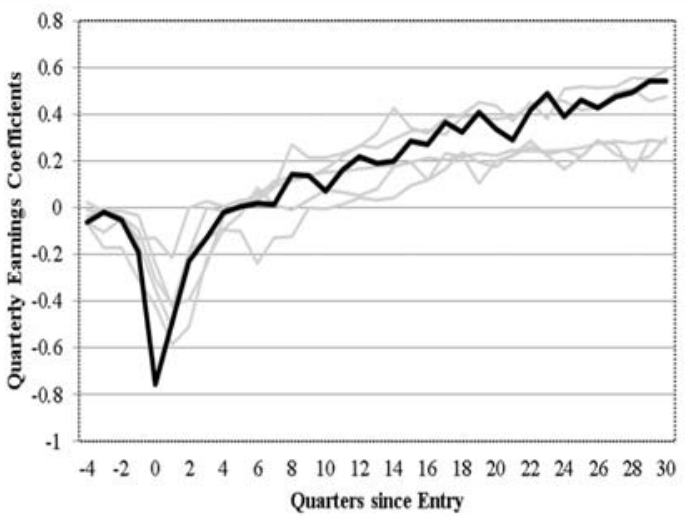

Other

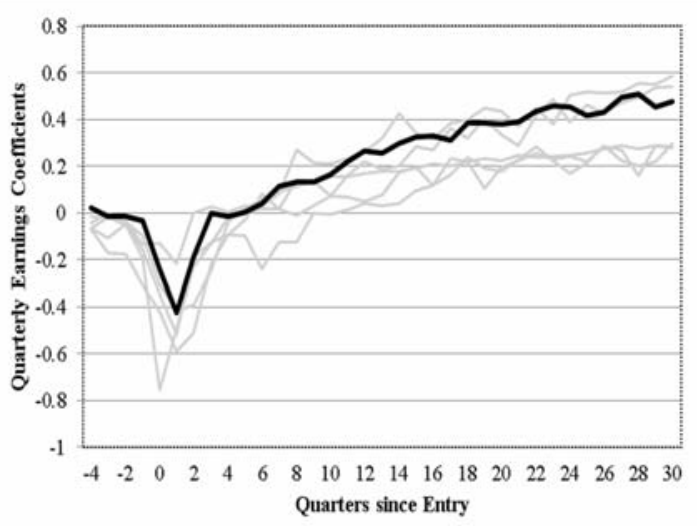


Figure 5 - Effect of Attendance on Earnings by Quarter, Men and Women, Weighted by Field of Study, Certificate Programs

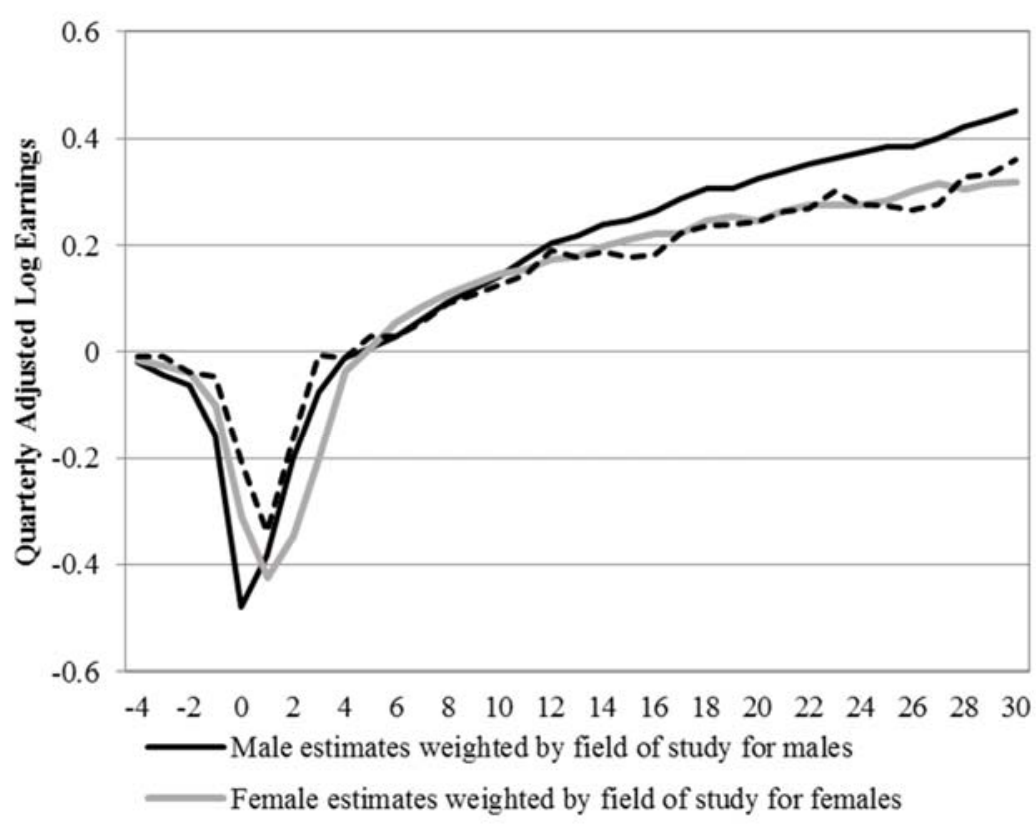

- - - Male estimates weighted by field of study for females

Figure 6 - Effect of Attendance on Earnings by Quarter, Men and Women, Weighted by Field of Study, Associate’s Degree Programs

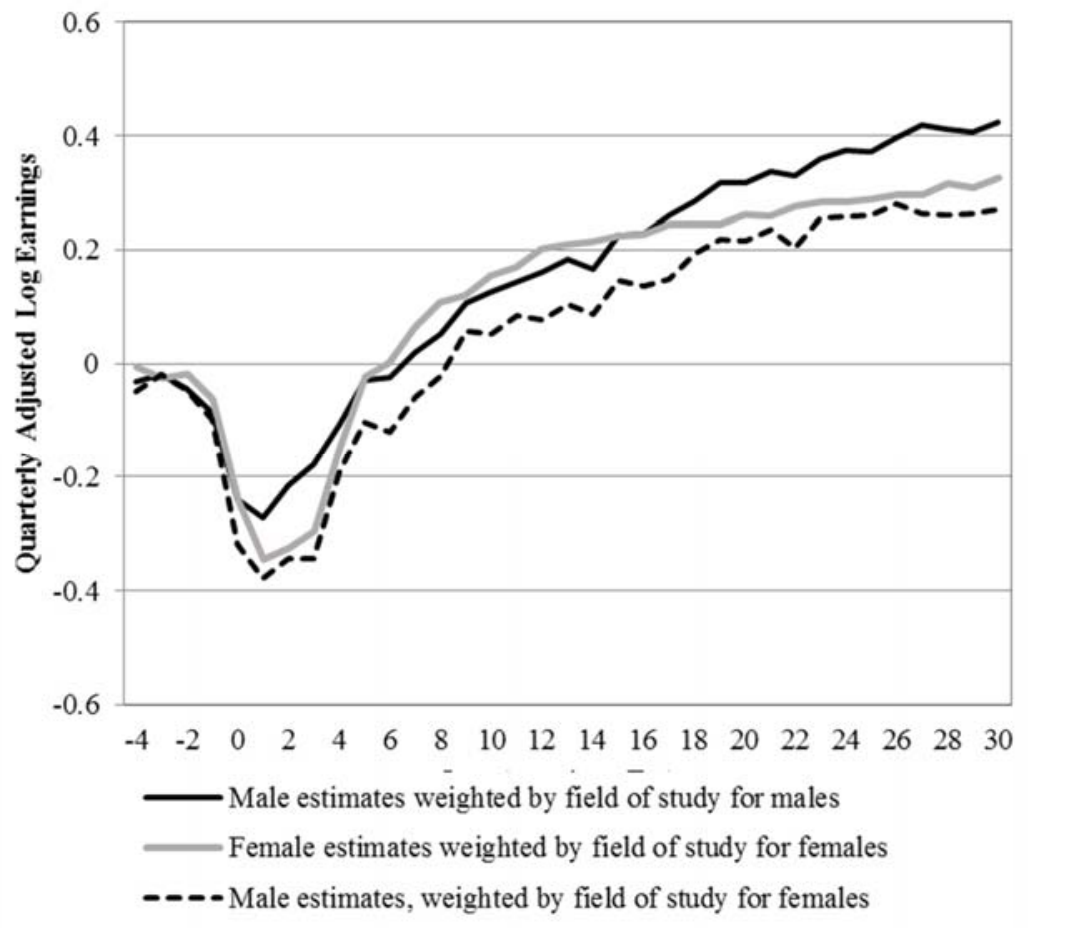


Table 1 - Descriptive Statistics by Gender and Program Type

\begin{tabular}{|c|c|c|c|c|}
\hline \multirow[b]{3}{*}{ Variable } & \multicolumn{2}{|c|}{ Men } & \multicolumn{2}{|c|}{ Women } \\
\hline & Certificate & $\underline{\text { Associate's }}$ & Certificate & Associate's \\
\hline & Mean & Mean & Mean & Mean \\
\hline \multicolumn{5}{|c|}{ Demographics and Schooling Information } \\
\hline White & 0.666 & 0.594 & 0.565 & 0.636 \\
\hline Black & 0.272 & 0.270 & 0.367 & 0.284 \\
\hline Other / Missing Race & 0.063 & 0.136 & 0.068 & 0.080 \\
\hline \multirow[t]{2}{*}{ Age at time of entry } & 32.7 & 27.0 & 29.3 & 27.3 \\
\hline & $(10.7)$ & $(8.0)$ & (9.9) & (8.4) \\
\hline Less than high school & 0.066 & 0.018 & 0.070 & 0.026 \\
\hline High school & 0.721 & 0.767 & 0.769 & 0.797 \\
\hline GED & 0.193 & 0.209 & 0.153 & 0.167 \\
\hline Missing education & 0.020 & 0.006 & 0.008 & 0.009 \\
\hline Entry year 2005 & 0.210 & 0.214 & 0.214 & 0.215 \\
\hline Entry year 2006 & 0.211 & 0.180 & 0.199 & 0.204 \\
\hline Entry year 2007 & 0.190 & 0.161 & 0.190 & 0.173 \\
\hline Entry year 2008 & 0.178 & 0.222 & 0.192 & 0.203 \\
\hline Entry year 2009 & 0.210 & 0.222 & 0.205 & 0.205 \\
\hline Major Urban & 0.684 & 0.742 & 0.709 & 0.716 \\
\hline Not Major Urban & 0.316 & 0.258 & 0.291 & 0.284 \\
\hline \multicolumn{5}{|l|}{ Schooling Information } \\
\hline Studying business & 0.038 & 0.101 & 0.069 & 0.132 \\
\hline Studying computers & 0.038 & 0.276 & 0.016 & 0.045 \\
\hline Studying health & 0.139 & 0.179 & 0.747 & 0.617 \\
\hline Studying trades & 0.329 & 0.037 & 0.016 & 0.003 \\
\hline Studying transport & 0.323 & 0.000 & 0.028 & 0.000 \\
\hline Studying other & 0.133 & 0.407 & 0.124 & 0.204 \\
\hline Completed certificate & 0.700 & 0.015 & 0.616 & 0.032 \\
\hline Completed associate's & 0.008 & 0.434 & 0.016 & 0.501 \\
\hline Missing completion info & 0.292 & 0.545 & 0.368 & 0.455 \\
\hline Number of Students & 22,648 & 7,079 & 26,738 & 12,264 \\
\hline
\end{tabular}

Note: Standard deviation for age is in parentheses. 
Table 2 - Descriptive Statistics for Outcomes by Gender and Program Type

\begin{tabular}{|c|c|c|c|c|c|c|c|c|}
\hline \multirow[b]{3}{*}{ Variable } & \multicolumn{4}{|c|}{ Men } & \multicolumn{4}{|c|}{ Women } \\
\hline & \multicolumn{2}{|c|}{ Certificate } & \multicolumn{2}{|c|}{ Associate's } & \multicolumn{2}{|c|}{ Certificate } & \multicolumn{2}{|c|}{ Associate's } \\
\hline & Mean & Std Dev & Mean & Std Dev & Mean & Std Dev & Mean & Std Dev \\
\hline \multicolumn{9}{|l|}{ Earnings } \\
\hline 3-24 quarters before entry & 3,806 & 5,096 & 2,357 & 2,757 & 2,340 & 2,900 & 2,254 & 2,372 \\
\hline 2 quarters before entry & 4,338 & 9,087 & 2,918 & 4,544 & 2,671 & 4,576 & 2,726 & 4,947 \\
\hline 1 quarter before entry & 4,093 & 10,569 & 2,862 & 4,893 & 2,616 & 5,292 & 2,643 & 4,495 \\
\hline Quarter of entry & 3,629 & 13,069 & 2,555 & 4,676 & 2,152 & 4,670 & 2,242 & 3,827 \\
\hline 1 quarter after entry & 3,268 & 8,178 & 2,537 & 3,869 & 2,040 & 4,016 & 2,108 & 3,139 \\
\hline 2 quarters after entry & 3,657 & 7,206 & 2,707 & 3,851 & 2,206 & 3,864 & 2,208 & 3,202 \\
\hline 3 quarters after entry & 4,009 & 7,474 & 2,919 & 4,183 & 2,414 & 4,097 & 2,317 & 2,989 \\
\hline 4 quarters after entry & 4,182 & 7,937 & 2,979 & 4,221 & 2,713 & 4,021 & 2,423 & 3,415 \\
\hline 5-8 quarters after entry & 4,574 & 5,814 & 3,358 & 3,499 & 3,217 & 3,531 & 2,940 & 2,849 \\
\hline 9-20 quarters after entry & 5,457 & 6,189 & 4,407 & 3,793 & 3,809 & 3,650 & 3,951 & 3,177 \\
\hline \multirow[t]{2}{*}{ 21-30 quarters after entry } & 6,647 & 7,883 & 5,775 & 4,755 & 4,488 & 4,111 & 4,755 & 3,770 \\
\hline & \multicolumn{2}{|c|}{ Mean } & \multicolumn{2}{|c|}{ Mean } & \multicolumn{2}{|c|}{ Mean } & \multicolumn{2}{|c|}{ Mean } \\
\hline \multicolumn{9}{|l|}{ Employment } \\
\hline 3-24 quarters before entry & \multicolumn{2}{|c|}{0.898} & \multicolumn{2}{|c|}{0.871} & \multicolumn{2}{|c|}{0.896} & \multicolumn{2}{|c|}{0.906} \\
\hline 2 quarters before entry & \multicolumn{2}{|c|}{0.678} & \multicolumn{2}{|c|}{0.663} & \multicolumn{2}{|c|}{0.665} & \multicolumn{2}{|c|}{0.702} \\
\hline 1 quarter before entry & \multicolumn{2}{|c|}{0.663} & \multicolumn{2}{|c|}{0.669} & \multicolumn{2}{|c|}{0.657} & \multicolumn{2}{|c|}{0.699} \\
\hline Quarter of entry & \multicolumn{2}{|c|}{0.621} & \multicolumn{2}{|c|}{0.664} & \multicolumn{2}{|c|}{0.612} & \multicolumn{2}{|c|}{0.675} \\
\hline 1 quarter after entry & \multicolumn{2}{|c|}{0.604} & & 67 & & 98 & & 59 \\
\hline 2 quarters after entry & & & & 79 & & 11 & & 60 \\
\hline 3 quarters after entry & & & & 91 & & 43 & & 68 \\
\hline 4 quarters after entry & & & & 89 & & & & 73 \\
\hline 5-8 quarters after entry & & & & 51 & & & & 65 \\
\hline 9-20 quarters after entry & & & & 62 & & & & 68 \\
\hline 21-30 quarters after entry & & & & 67 & & & & 71 \\
\hline
\end{tabular}


Appendix Table A1 - Effect of Proprietary School Attendance on Log Quarterly Earnings

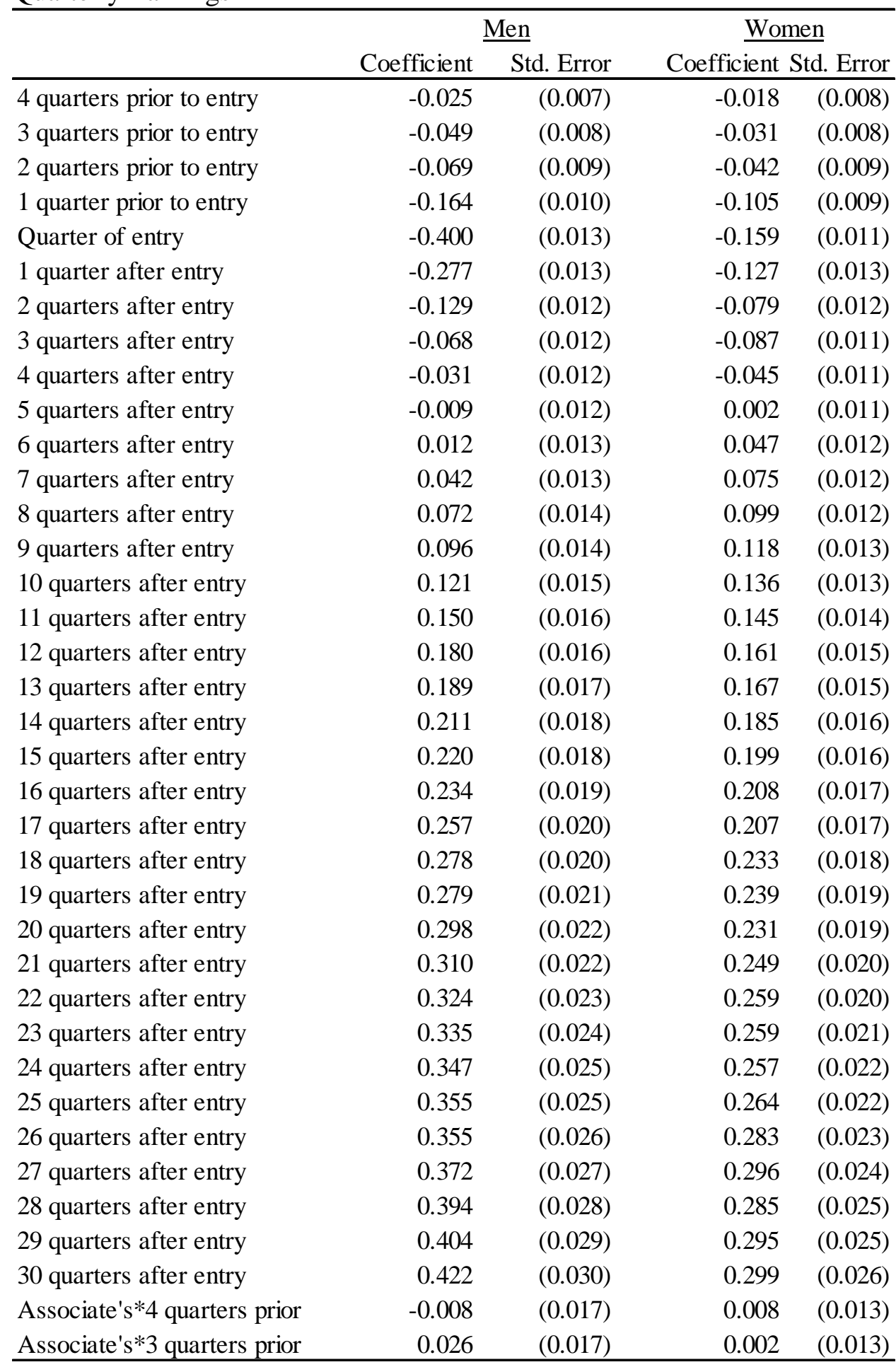


Appendix Table A1 (Cont'd) - Effect of Proprietary School Attendance on Log Quarterly Earnings

\begin{tabular}{|c|c|c|c|c|}
\hline & \multicolumn{2}{|c|}{ Men } & \multicolumn{2}{|c|}{$\underline{\text { Women }}$} \\
\hline & Coefficient & Std. Error & Coefficient & Std. Error \\
\hline Associate's*2 quarters prior & 0.023 & $(0.017)$ & 0.018 & $(0.013)$ \\
\hline Associate's*1 quarter prior & 0.077 & $(0.018)$ & 0.035 & $(0.014)$ \\
\hline Associate's*quarter of entry & 0.235 & $(0.022)$ & 0.062 & $(0.018)$ \\
\hline Associate's*1 quarter after & 0.160 & $(0.025)$ & 0.077 & $(0.021)$ \\
\hline Associate's*2 quarters after & 0.069 & $(0.022)$ & 0.048 & $(0.018)$ \\
\hline Associate's*3 quarters after & 0.030 & $(0.021)$ & 0.062 & $(0.017)$ \\
\hline Associate's*4 quarters after & -0.015 & $(0.020)$ & 0.012 & $(0.016)$ \\
\hline Associate's*5 quarters after & -0.020 & $(0.020)$ & -0.039 & $(0.015)$ \\
\hline Associate's*6 quarters after & -0.028 & $(0.019)$ & -0.058 & $(0.015)$ \\
\hline Associate's*7 quarters after & -0.011 & $(0.019)$ & -0.023 & $(0.014)$ \\
\hline Associate's*8 quarters after & -0.010 & $(0.019)$ & -0.005 & $(0.014)$ \\
\hline Associate's*9 quarters after & 0.018 & $(0.018)$ & -0.013 & $(0.014)$ \\
\hline Associate's*10 quarters after & 0.014 & $(0.018)$ & 0.004 & $(0.014)$ \\
\hline Associate's*11 quarters after & -0.001 & $(0.018)$ & 0.008 & $(0.014)$ \\
\hline Associate's*12 quarters after & -0.014 & $(0.018)$ & 0.021 & $(0.014)$ \\
\hline Associate's*13 quarters after & 0.000 & $(0.018)$ & 0.023 & $(0.014)$ \\
\hline Associate's*14 quarters after & -0.037 & $(0.018)$ & 0.011 & $(0.014)$ \\
\hline Associate's*15 quarters after & 0.014 & $(0.018)$ & 0.006 & $(0.014)$ \\
\hline Associate's*16 quarters after & 0.000 & $(0.018)$ & -0.004 & $(0.014)$ \\
\hline Associate's*17 quarters after & 0.009 & $(0.018)$ & 0.017 & $(0.014)$ \\
\hline Associate's*18 quarters after & 0.013 & $(0.018)$ & -0.011 & $(0.014)$ \\
\hline Associate's*19 quarters after & 0.040 & $(0.018)$ & -0.018 & $(0.014)$ \\
\hline Associate's*20 quarters after & 0.020 & $(0.018)$ & 0.006 & $(0.014)$ \\
\hline Associate's*21 quarters after & 0.026 & $(0.018)$ & -0.015 & $(0.014)$ \\
\hline Associate's*22 quarters after & 0.004 & $(0.018)$ & -0.009 & $(0.014)$ \\
\hline Associate's*23 quarters after & 0.021 & $(0.018)$ & -0.002 & $(0.014)$ \\
\hline Associate's*24 quarters after & 0.022 & $(0.018)$ & -0.001 & $(0.015)$ \\
\hline Associate's*25 quarters after & 0.009 & $(0.019)$ & -0.004 & $(0.015)$ \\
\hline Associate's*26 quarters after & 0.036 & $(0.019)$ & -0.015 & $(0.015)$ \\
\hline Associate's*27 quarters after & 0.042 & $(0.019)$ & -0.028 & $(0.016)$ \\
\hline Associate's*28 quarters after & 0.007 & $(0.021)$ & 0.004 & $(0.016)$ \\
\hline Associate's*29 quarters after & -0.006 & $(0.021)$ & -0.019 & $(0.017)$ \\
\hline Associate's*30 quarters after & -0.009 & $(0.022)$ & -0.003 & $(0.017)$ \\
\hline Enrolled & -0.152 & $(0.013)$ & -0.311 & $(0.012)$ \\
\hline Associate's*Enrolled & 0.001 & $(0.022)$ & 0.008 & $(0.019)$ \\
\hline $\mathrm{N}$ & & & 1,8 & 150 \\
\hline Adj R-squared & & 019 & 0.0 & 6 \\
\hline
\end{tabular}

Notes: Standard errors are clustered at the individual level. In addition to the variables shown, all models also contain controls for age as a cubic, and person and calendar quarter fixed effects. 
Appendix Figure A1 - Quarterly Earnings by Program Type and Quarters since School Entry, Men Completing Degrees

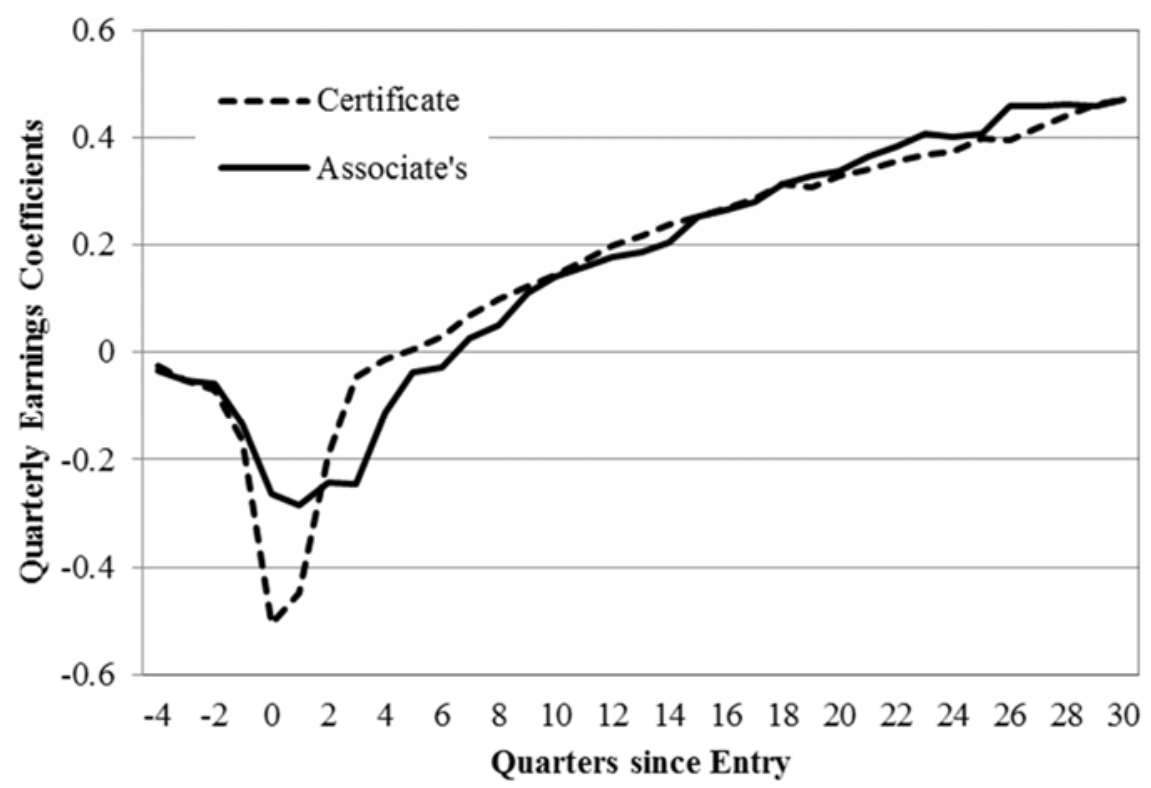

Appendix Figure A2 - Quarterly Earnings by Program Type and Quarters since School Entry, Women Completing Degrees

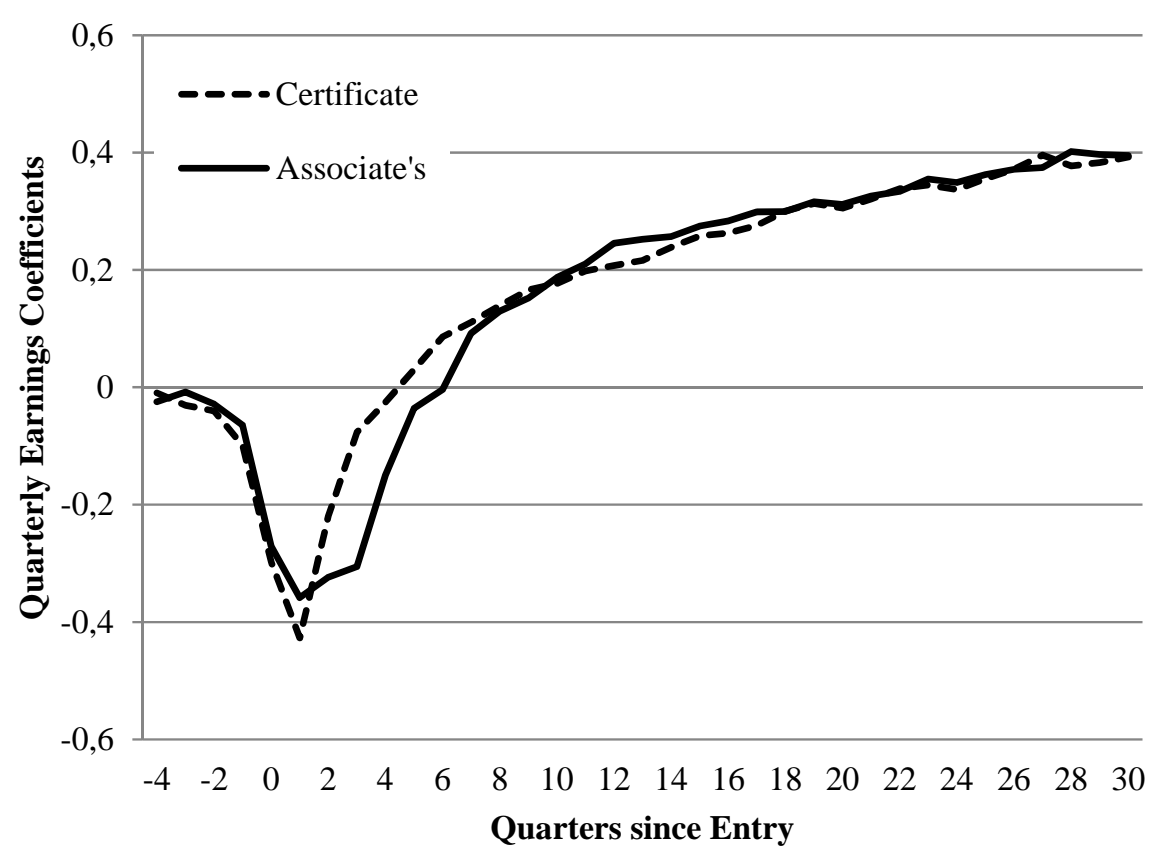


Appendix Figure A3 - Effect of Attendance on Employment by Quarter, Men in Certificate Programs, Different Samples

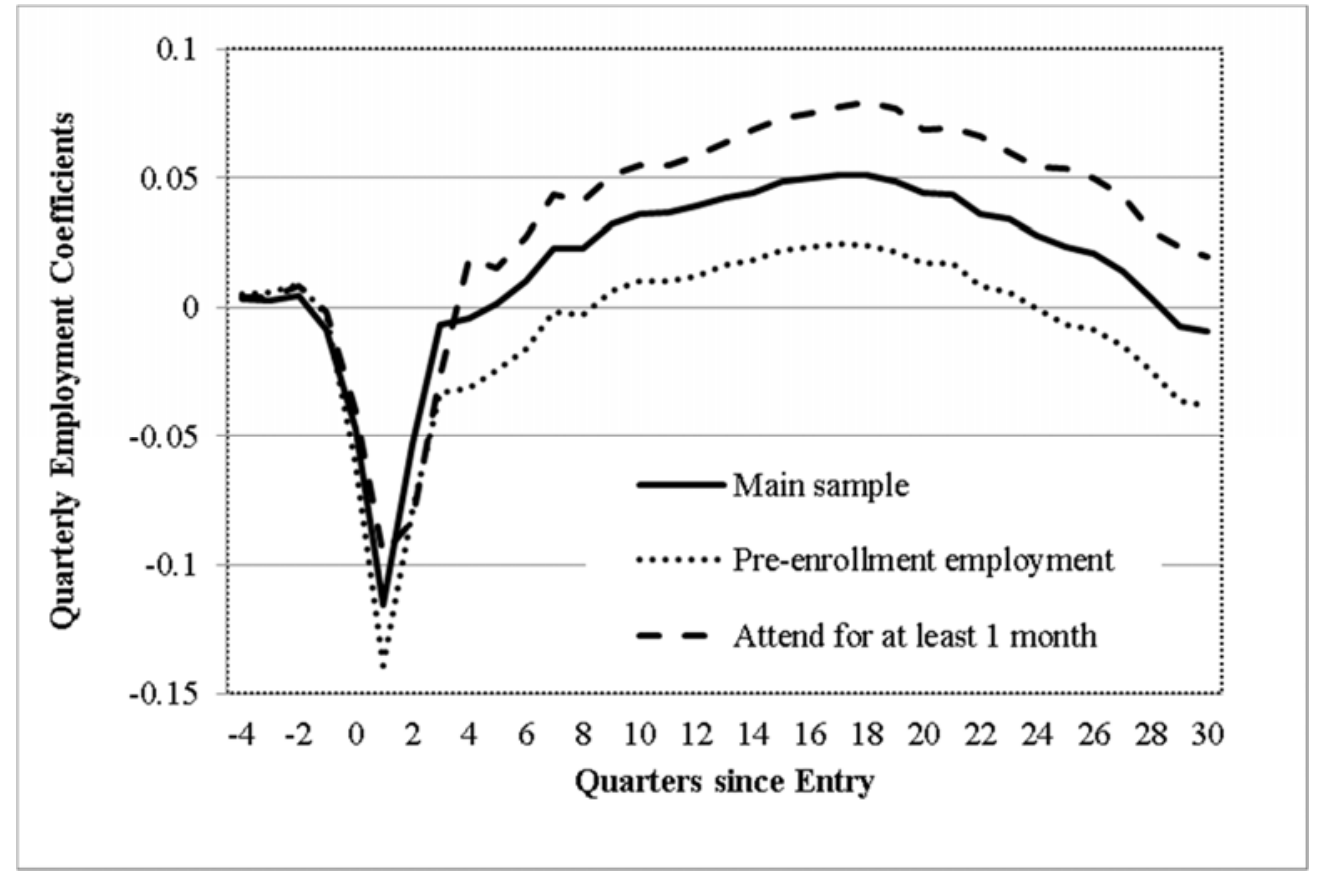

Appendix Figure A4 - Effect of Attendance on Employment by Quarter, Women in Certificate Programs, Different Samples

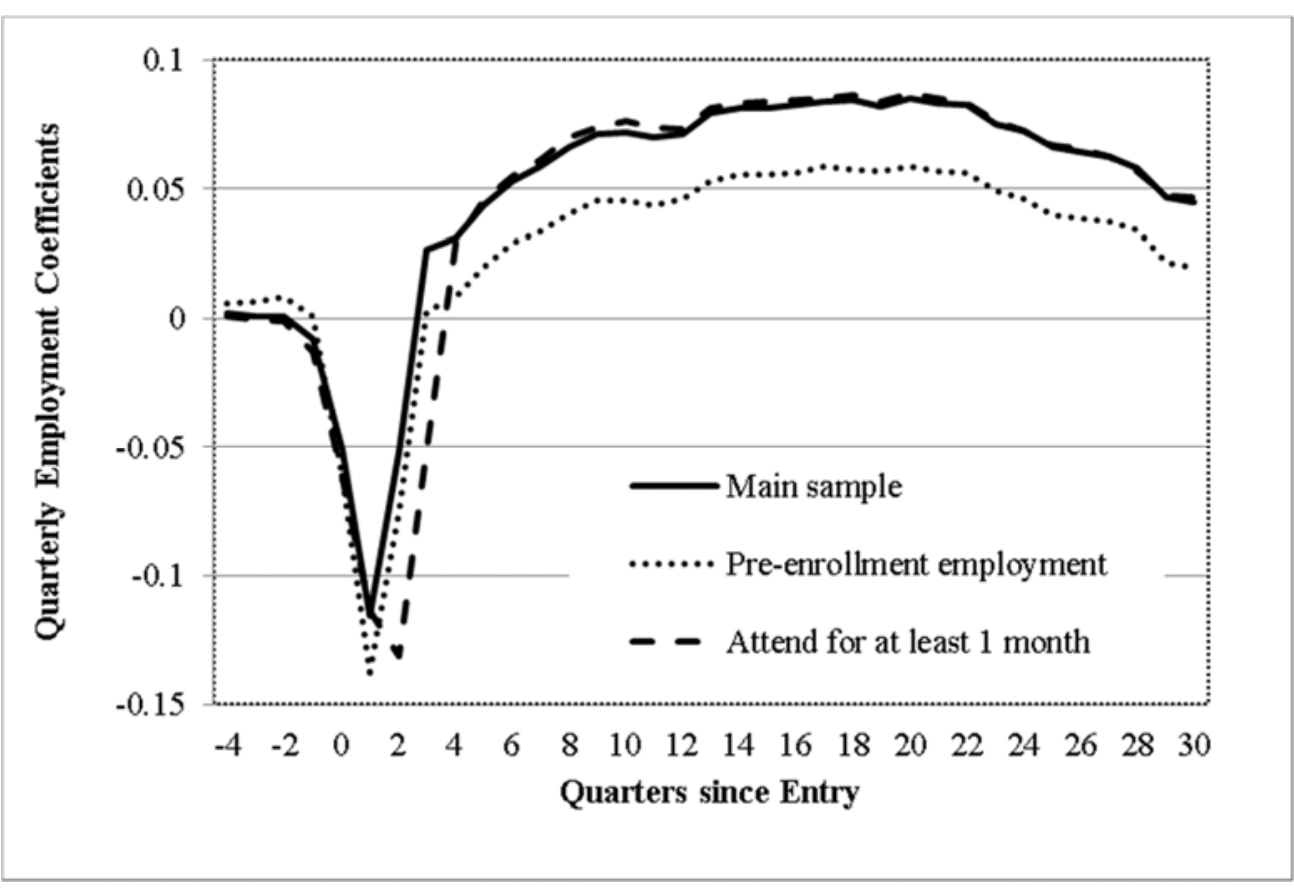

